\title{
Technological Development and Medical Productivity: The Diffusion of Angioplasty in New York State
}

\section{Citation}

Cutler, David and Robert Huckman. 2003. Technological development and medical productivity: The diffusion of angioplasty in New York state. Journal of Health Economics 22(2): 187-217.

\section{Published Version}

http://dx.doi.org/10.1016/S0167-6296(02)00125-X

\section{Permanent link}

http://nrs.harvard.edu/urn-3:HUL.InstRepos:2664291

\section{Terms of Use}

This article was downloaded from Harvard University's DASH repository, and is made available under the terms and conditions applicable to Other Posted Material, as set forth at http:// nrs.harvard.edu/urn-3:HUL.InstRepos:dash.current.terms-of-use\#LAA

\section{Share Your Story}

The Harvard community has made this article openly available. Please share how this access benefits you. Submit a story.

Accessibility 
NBER WORKING PAPER SERIES

\title{
TECHNOLOGICAL DEVELOPMENT AND MEDICAL PRODUCTIVITY: DIFFUSION OF ANGIOPLASTY IN NEW YORK STATE
}

\author{
David M. Cutler \\ Robert S. Huckman \\ Working Paper 9311 \\ http://www.nber.org/papers/w9311 \\ NATIONAL BUREAU OF ECONOMIC RESEARCH \\ 1050 Massachusetts Avenue \\ Cambridge, MA 02138 \\ October 2002
}

The views presented in this paper do not necessarily reflect the findings of the New York State Department of Health or the New York State Cardiac Advisory Committee. We thank Thomas McGuire, Joseph Newhouse, two anonymous referees, and participants in the BU/Harvard/MIT Health Economics Seminar for helpful comments. We also thank Jeff Geppert for assistance in obtaining data. The views expressed herein are those of the authors and not necessarily those of the National Bureau of Economic Research.

(C) 2002 by David M. Cutler and Robert S. Huckman. All rights reserved. Short sections of text, not to exceed two paragraphs, may be quoted without explicit permission provided that full credit, including (C) notice, is given to the source. 
Technological Development and Medical Productivity: The Diffusion of Angioplasty

in New York State

David M. Cutler

Robert S. Huckman

NBER Working Paper No. 9311

October 2002

JEL No. I1, O3

\begin{abstract}
$\underline{\text { ABSTRACT }}$
A puzzling feature of many medical innovations is that they simultaneously appear to reduce unit costs and increase total costs. We consider this phenomenon by examining the diffusion of percutaneous transluminal coronary angioplasty (PTCA) — a treatment for coronary artery disease — over the past two decades. We find that growth in the use of PTCA led to higher total costs despite its lower unit cost. Over the two decades following PTCA's introduction, however, we find that the magnitude of this increase was reduced by between $10 \%$ and $20 \%$ due to the substitution of PTCA for CABG. In addition, the increased use of PTCA appears to be a productivity improvement. PTCAs that substitute for CABG cost less and have the same or better outcomes, while PTCAs that replace medical management appear to improve health by enough to justify the cost.
\end{abstract}

David M. Cutler

Department of Economics

Harvard University

Cambridge, MA 02138

and NBER

dcutler@harvard.edu
Robert S. Huckman

T17 Morgan Hall

Harvard Business School

Boston, MA 02163

rhuckman@hbs.edu 


\section{INTRODUCTION}

The dramatic technological change in the medical care industry has raised two key questions for patients, firms, and policymakers. First, what are implications of technological growth for the cost of care? Second, what are its effects on the quality of care? Considered in tandem, the answers to these questions illustrate the impact of technology on medical productivity. That is, they allow us to consider whether medical innovation is "worth it" in terms of increasing the level of quality-adjusted output per unit of cost.

Much of the health economics literature subscribes to the view that technological innovation is a primary driver of increasing medical costs in the United States. ${ }^{1}$ Fuchs (1986) suggests that the American medical establishment is infused with a "technological imperative"the belief that if a clinical intervention is possible and safe, it should be undertaken without regard for its costs and benefits. Other economic studies (Weisbrod, 1991; Newhouse, 1992; Cutler and McClellan, 1998) have also noted a positive relationship between technological growth and medical costs. What is somewhat puzzling about this positive relationship is that it appears to apply to many innovations that are actually less costly on a per-unit basis than existing technologies for which they are a substitute.

A key to understanding this puzzle is the phenomenon of treatment expansion-the provision of more intensive treatment to patients with low-grade symptoms (Cutler and McClellan, 2001). For example, prior to the early 1980s, patients with severe coronary artery disease (CAD) would receive coronary artery bypass graft (CABG) surgery, a major procedure that involves grafting a portion of vein or artery to bypass blockage in the coronary artery.

\footnotetext{
${ }^{1}$ Several authors (e.g., Garber, 1994; Gelijns and Rosenberg, 1994) have noted the contrast between this view and the common assertion of many economists outside of the health arena-that technological innovation
} 
Those with more mild CAD would undergo less costly (and less traumatic) medical management. The introduction of percutaneous trans luminal coronary angioplasty (PTCA) in the late 1970s and early 1980s provided an intermediate treatment with cost and intensity levels that fell in between those of CABG and medical management. In contrast to CABG, PTCA involves only a small incision through which a balloon-tipped catheter is threaded. Upon reaching the point of blockage, the balloon is inflated to restore blood flow.

In this case, treatment expansion occurred among those PTCA patients who would have otherwise received only medical treatment. ${ }^{2}$ To the extent that some patients receive more intensive interventions, such expansion increases total costs and may have either positive or negative effects on outcomes. Treatment substitution-which allows a patient to shift from more- to less-intensive interventions - serves to offset the cost increases associated with expansion. Returning to the PTCA example, substitution involved some patients receiving PTCA in lieu of CABG. In theory, the effect of substitution-and the combined effect of expansion and substitution—on both costs and outcomes is ambiguous.

Beyond the ambiguity surrounding the offsetting effects of treatment expansion and substitution at a given point in time, one must also consider whether the relative magnitudes of these effects change over time. The equilibrium costs and benefits associated with many innovations are not evident at the time of their introduction (Gelijns and Rosenberg, 1994). As uncertainty is resolved over time - either through learning or exogenous factors — the relationship between the marginal benefit and marginal cost of a technology may change. This

increases productivity. Even the non-health literature, however, includes examples that question the ability of certain types of innovation to improve productivity (e.g., Berndt and Morrison, 1995).

${ }^{2}$ Similarly, Legorreta et al. (1993) find that the diffusion of laparoscopic cholecystectomy, a less expensive and invasive alternative to traditional gall bladder surgery, initially led to increased total costs for the treatment of gall bladder disease. This result is due to an increase in the rate of cholecystectomy procedures among patients with 
may be the case for surgical procedures for which outcomes improve (and unit costs decline) with volume ${ }^{3}$ or for pharmaceuticals that are found to be effective for new indications over time. As such, the instantaneous productivity of a medical innovation measured shortly after its introduction might differ substantially from that measured at a later date.

In this paper, we address this issue of time-varying effects by examining the use of PTCA and CABG over the past two decades. PTCA is an innovation that is characterized by the uncertainty described above. Specifically, despite its advantages in terms of cost and patient comfort, PTCA initially was considered less effective than CABG for patients with relatively severe CAD. Due to learning and technological improvements over time, however, PTCA began to be used on increasingly severe cases that were previously reserved for CABG. In short, PTCA appears to have become a stronger substitute for CABG over time (Bohmer, Christensen, and Kenagy, 2000).

We use patient-level data from the State of New York to examine the utilization patterns for PTCA and CABG from 1982 to 2000. The beginning of this period roughly corresponds to the point at which PTCA was introduced into mainstream medical practice in the United States. We identify two distinct phases in the diffusion of PTCA. The 1980s constitute a period of treatment expansion during which the overall utilization rates for both PTCA and CABG increased. During the 1990s, however, we find evidence of treatment substitution as the utilization rates for PTCA and CABG increased and decreased, respectively. While the introduction of PTCA raised total costs via treatment expansion, this increase was offset over

mild disease who previously would not have undergone traditional surgery.

${ }^{3}$ Luft, Bunker, and Enthoven (1979), Luft, Hunt, and Maerki (1987) and Farley and Ozminkowski (1992) examine volume-outcome relationships across several diagnoses and procedures. Showstack et al. (1987) and Hannan et al. (1991) consider these relationships for CABG, while Hannan et al. (1997) and Ho (2000) examine them with respect to PTCA. 
time due to the substitution of PTCA for CABG. Though we must make several assumptions to consider the impact of PTCA on outcomes during the initial years of its diffusion, we find evidence that the expanded use of PTCA on patients who previously would have received only medical treatment appears to have improved the quality of care. Further, we present preliminary evidence suggesting that the substitution of PTCA for CABG eventually improved quality for patients receiving revascularization (i.e., either CABG or PTCA). Our results suggest that new technologies have the potential to become increasingly less costly over time and may result in productivity improvements.

The remainder of this paper is organized in four sections. Section II provides background on PTCA and its diffusion over the past two decades. Section III discusses issues related to our empirical methodology. Section IV provides detail and descriptive analysis concerning the data from New York. Section V presents our results, and Section VI concludes.

\section{THE DEVELOPMENT AND GROWTH OF PTCA}

Prior to the early 1980 s, patients with CAD were faced with two possible paths of treatment. The decision between these paths typically depended on the severity of a patient's illness. Those with relatively mild CAD might pursue medical management (i.e., they would not receive any invasive procedures), while those with more advanced disease would undergo CABG. As noted above, CABG was traumatic for patients and not infrequently resulted in death. Nonetheless, it was found to be a relatively effective method for treating severe CAD. PTCA was first performed in the United States in 1978 and entered mainstream medical practice during the 1980s. While less invasive, traumatic, and costly than CABG, PTCA does 
involve the risk of restenosis, or return of blockage to the artery. In addition, a PTCA procedure may dislodge a portion of blockage, thereby creating a new clot in a different location. During the years immediately following its introduction, PTCA was associated with relatively high rates of restenosis and mortality (Williams et al., 2000). As such, its initial use was primarily limited to patients with relatively mild CAD (Hillis and Rutherford, 1994). Patients with more severe blockage continued to be treated primarily with CABG.

Over time, PTCA outcomes have improved due to both learning (Hannan et al., 1997; Ho, 2000) and exogenous technological change. Perhaps the most important improvement to PTCA was the introduction of coronary stents in the mid-1990s. Stents are small coils that are inserted to prop open an artery after PTCA. They have reduced the occurrence of restenosis and other adverse outcomes, such as mortality, myocardial infarction, or emergency CABG (Serruys et al., 1998). Given their ability to improve PTCA outcomes, stents were adopted very quickly by cardiologists. In 1993, only one percent of PTCA patients in New York received a stent; this figure increased to $29 \%$ and $71 \%$ by 1995 and 1997 , respectively. ${ }^{4}$ As a result of the improved outcomes associated with PTCA over time, the procedure has become increasingly substitutable with $\mathrm{CABG}$ for patients with relatively severe CAD.

\section{EMPIRICAL METHODOLOGY}

\section{The Impact of PTCA on Cost}

\footnotetext{
${ }^{4}$ Stent procedures did not receive a unique procedure code under the International Classification of Diseases, $9^{\text {th }}$ Revision (ICD-9) until 1995. The rates for 1993 and 1995 are based on data from New York's Coronary Angioplasty Reporting System, which asks cardiologists whether a stent was used in each procedure. The 1997 figure is based on ICD-9 codes reported in the Statewide Planning and Resource Cooperative System. These data are described in greater detail in Section III.
} 
The first part of our empirical analysis considers the impact of PTCA's diffusion on the cost of treating patients with CAD. We assume that the primary driver of PTCA's impact on total cost is its effect on the rate at which both PTCA and CABG are provided for a fixed population. Increased PTCA use may also affect the cost-per-PTCA or cost-per-CABG due, for example, to volume-cost effects. While our analysis does not capture this latter impact on cost, it is likely that such volume-cost effects will be more substantial for the younger technologyPTCA—than for the more mature CABG. Assuming that PTCA is, on average, less costly than CABG, the additional affect due to this volume-cost relationship would work in the same direction as the "static" effect of replacing CABG procedures with PTCAs.

While the discharge data from New York allows us to observe all of the procedures provided over nearly two decades, it offers only limited data about the clinical characteristics of individual patients. We thus focus our analysis on county-level data, as we expect the average unobservable characteristics to remain relatively constant within counties over time. This analysis enables us to exploit variation in transitory changes in utilization across different regions of New York.

Using annual county-level observations, we estimate changes in the degree of substitution between $\mathrm{CABG}$ and PTCA over time. First, we regress the CABG rate per person age 45 years and older on the PTCA rate and a vector of controls. Patients in this age category accounted for over 95\% of the CABG and PTCA procedures in New York during 2000 (New York State Department of Health, 1982-2000). The exact specification of this regression is:

$$
(C A B G / P O P)_{i t}=a_{i}+d_{t}+\beta\left[(P T C A / P O P)_{i t} * Y E A R_{i t}\right]+? X_{i t}+e_{i t}
$$


The variables in (1) are indexed by year, $t$, and county of patient residence, $i$. This specification includes county fixed effects, $\alpha_{i}$, to capture time-invariant factors that may affect the rate of CABG use in a given area. Year fixed effects, $\delta_{t}$, are included to control for statewide changes in the average $\mathrm{CABG}$ rate over time. We use the county of patient residence rather than the county of hospital admission as the unit of analysis, as many hospitals draw patients from areas outside of the county in which they are located.

The key independent variables in (1) are the interactions of $(P T C A / P O P)_{i t}$ the PTCA rate per 1,000 population age 45 and older-with $Y E A R_{i t}$, a vector of indicators for three-year periods between 1985 and 2000. The coefficient vector, $\beta$, thus reflects the degree of substitution between PTCA and CABG over time, with positive (negative) values of its elements implying that the two procedures are complements (substitutes). By using a time-varying coefficient, we allow the degree of substitution between these procedures to change as uncertainty about the costs and benefits of PTCA is resolved.

$X_{i t}$ is a vector of controls for the demographic characteristics of a given county. It includes the rate of total hospital discharges per 100,000 population-of all ages, not just 45 and older-to control for shifts in the overall utilization of hospital services in a given area. In addition, $X_{i t}$ contains the percentage of county $i$ 's population that falls into each of three age groups: younger than 45, 45-64, and 65 or older. Finally, $X_{i t}$ includes the percentage of hospital discharges for county residents that are covered by Medicare, Medicaid, and HMO payers, respectively. Medicare or Medicaid HMO patients are included in the Medicare and Medicaid categories, respectively. These payer mix variables are measured using all inpatient discharges, not simply those for cardiac patients. Certain versions of (1) include interactions of both the payer mix and age variables with three-year time periods. 
The county fixed effects in (1) account for constant differences in CABG and PTCA rates across geographies. As such, the coefficient vector, $\beta$, is identified by changes in the levels of procedure use. This specification controls for the fact that certain populations may be sicker on average than others. Alternatively, one might want to control for constant trends in procedure use across counties. This latter specification assumes not that certain populations are sicker than others, but that these groups may differ systematically in the degree to which they embrace new technologies. For example, patients or physicians in certain counties may be more willing than those in others to take the risks associated with new techniques that have uncertain costs and benefits. We, therefore, estimate a second version of (1) in which the CABG, PTCA, and total discharge variables are expressed as one-period changes. We refer to the resulting two models as the "levels" and "changes" specifications, respectively. Due to differencing, the sample size is reduced by one observation per county in the latter regression.

To the extent that unobservable factors are correlated with both the CABG and PTCA rate in a given county, the coefficient vector $\beta$ may be biased. For instance, primary care physicians in a given county may have a bias toward medical management of CAD, which would appear as a reduction in the use of both CABG and PTCA relative to other areas. We consider a simple example with only two time periods and, hence, only two PTCA-time interactions.

Defining $p_{i t}=(P T C A / P O P)_{i t}$, the expected value of the coefficient for the first time period, $\hat{\beta_{1}}$, is:

$$
E\left(\hat{\beta_{1}}\right)=\beta_{l}+E\left(\frac{\sum p_{i 1} e_{i 1}}{\sum p_{i l}^{2}}\right)
$$

Similarly, the coefficient for the second period, $\hat{\beta}_{2}$, would be:

$$
E\left(\hat{\beta_{2}}\right)=\beta_{2}+E\left(\frac{\sum p_{i 2} e_{i 2}}{\sum p_{i 2}^{2}}\right)
$$


In both (2) and (3), the bias is captured by the second term on the right-hand side, which, in general, is not equal to zero due to the correlation between $\varepsilon_{i t}$ and $p_{i t}$.

For the purposes of this study, however, we are interested in obtaining an unbiased estimate, not of $\beta$, but of the change in $\beta$ over time. Under the assumption that the unobservables have the same impact on technology utilization over time, the bias term is also constant, such that:

$$
E\left(\hat{\beta_{1}}-\hat{\beta_{2}}\right)=\beta_{1}-\beta_{2}
$$

Even if our above assumption is considered restrictive, we are not greatly concerned about the impact of this potential bias on our results, as it would likely have a greater impact on the level of $\beta$ rather than the change in $\beta$ over time.

\section{The Impact of PTCA on Outcomes}

Any assessment of medical productivity that considers only changes in costs, while ignoring effects on outcomes, is incomplete. We thus consider the degree to which increased PTCA use is correlated with improved outcomes for specified populations. A common measure of cardiac outcomes is risk-adjusted, in-hospital mortality, which we use to compare CABG and PTCA in Appendix A. In-hospital death is relatively rare for CABG and is even less frequent for PTCA. As such, one might be inclined to look at longer-term measures of risk-adjusted mortality (e.g., within one year of discharge) in hopes of obtaining less biased estimates of quality. Nevertheless, information on post-discharge mortality is not available in the New York databases. Even if information on long-term mortality were readily available, it still would not 
capture improvements in the quality of life that, while attributable to the growth in PTCA, did not affect mortality rates. We discuss our outcome measures at greater length in Section V.

\section{DATA AND DESCRIPTIVE ANALYSIS}

The main source of data for the cost analysis is New York's Statewide Planning and Resource Cooperative System (SPARCS). SPARCS provides patient-level demographic (e.g., age, sex, payer type) and administrative (e.g., diagnoses, procedures performed, and total charges) information for all inpatient hospital discharges. The earliest year for which this data is available is 1982. Our analysis covers all relevant discharges in New York from 1982 to 2000 with the exception of 1983 and 1984. These two years are excluded due to concerns about data integrity for CABG patients. ${ }^{5}$ Though the 1982 data appears consistent with the post-1984 trend, we are not certain if its integrity has been affected. Still, the results we report are robust to excluding the 1982 data.

We supplement our analyses using the SPARCS data with three years of clinical data from the Cardiac Surgery Reporting System (CSRS) and Coronary Angioplasty Reporting System (CARS) of the New York State Department of Heath (NYSDOH). Through its CSRS

\footnotetext{
${ }^{5}$ Statewide, the number of reported CABG procedures in both 1983 and 1984 is significantly higher than that in 1985. Specifically, the annual number of reported CABG discharges for residents of New York increases from roughly 6,600 in 1982 to 9,700 in 1983. This number then declines to 8,600 in 1984 and 8,400 in 1985. After 1985, the absolute number of reported CABG discharges increases monotonically until 1997. This trend is puzzling given the commonly held belief that the use of CABG was increasing throughout the 1980s and during much of the 1990s. After discussions with the administrators of the SPARCS data, we decided that 1983 and 1984 should be excluded from our analysis. The 1982 data may suffer from some underreporting, as 1982 was the first year of the SPARCS program. Nevertheless, the total CABG figure for 1982 appears to be consistent with both the trend in the data from 1985 to 2000 and with the fact that absolute CABG volumes were monotonically increasing during the 1980s.
} 
and CARS, NYSDOH collects detailed clinical data for every patient in New York receiving "isolated" CABG or PTCA procedures, respectively. Isolated procedures are those performed on patients who do not receive any other major heart surgeries, such as valve procedures, during the same admission (New York State Department of Health, 1998). The annual number of isolated CABG procedures in the state ranges from a low of 14,944 in 1991 to a high of 20,078 in 1996; for PTCA, these figures vary from 16,804 in 1993 to 21,707 in 1995 . These data provide clinical detail on pre-procedure risk factors as well as post-procedure outcomes including in-hospital mortality. Knowledge of each patient's pre-procedure risk factors allows for the determination of whether the average severity of patients undergoing each of these procedures changes over time. While the CABG data is available from 1991 to 1996 , the PTCA information covers only the period from 1993 to 1995 . Though limited, the timeframe for which PTCA data is available does cover a period during which one would have expected a large degree of substitution from CABG to PTCA as a result of the increased use of stents.

Figure 1 presents the annual rates of CABG and PTCA procedures for all New York residents performed in New York hospitals. These rates are expressed as the number of procedures per 1,000 population age 45 and older. ${ }^{6}$ During the period from 1985 to 1997 , the CABG and PTCA rates rise together, though the latter is increasing faster than the former. These different growth rates, combined with the fact that the CABG and PTCA rates move in opposite directions after 1997, serve as an initial indication that PTCA becomes a stronger substitute for CABG over time.

\footnotetext{
${ }^{6}$ Population figures for 1980, 1990, and 2000 were based on United States Census figures. Figures for 1991-1999 were based on estimates from the United States Census Bureau (website: http://www.census.gov/population/www/estimates/co_ca.html). Finally, annual figures for 1981 through 1989 were interpolated (linearly) using the actual Census figures for 1980 and 1990.
} 
Figure 2 provides further evidence of the increasing substitution of PTCA for CABG over time. Each observation corresponds to one of the 62 counties of patient residence in New York. The upper and lower panels show plots of the changes in PTCA and CABG rates from 1982 to 1993 and 1993 to 2000 , respectively. The time periods covered by these panels roughly correspond the pre- and post-stent eras in New York State. One would thus predict that the substitutability of CABG and PTCA would increase in the post-1993 period. The positive and significant slope of the simple regression line $(\beta=0.552$, standard error $=0.131)$ indicates a complementary relationship between CABG and PTCA in the years immediately following the introduction of PTCA. This finding corresponds to that obtained by Cutler and McClellan (1998) using data on AMI patients covered by Medicare during the period from 1984 to 1991. In the bottom panel, however, it is clear that a large number of counties shift from the upper-right to the lower-right quadrant. The slope of the simple regression line becomes smaller and insignificant $(\beta=0.067$, standard error $=0.077){ }^{7}$ This change suggests that the aggregate trends in PTCA and CABG use during the late 1990s also hold at the county level.

It is still possible that the patterns in Figures 1 and 2 do not actually represent substitution of PTCA for CABG. In particular, these trends are also consistent with a scenario in which PTCA is increasingly used for patients who would not have otherwise received CABG and CABG is simply performed on fewer patients with very severe conditions. Substitution would require that patients on the margin between CABG and PTCA (i.e., those with medium-severity CAD) become more likely to receive PTCA relative to CABG over time. Modifying an index developed by Mark et al. (1994), we divide patients into three severity categories: low, medium,

\footnotetext{
${ }^{7}$ The difference in the coefficients for the two time periods in statistically significant at the $1 \%$ level.
} 
and high. ${ }^{8}$ This categorization provides a rough control for the effects of any changes over time in the average severity of the population receiving revascularization. We then use the detailed clinical data for 1993 to 1995 to compare the number of patients within each severity group receiving PTCA versus $\mathrm{CABG}$ over time.

Panel A of Table 1 illustrates that both PTCA and CABG volumes increased in the period from 1993 to 1995, with the growth in PTCA exceeding that of CABG (i.e., 4,900 additional PTCAs versus 2,600 additional CABGs). These absolute changes translate into relative increases of approximately $29 \%$ and $16 \%$ for PTCA and CABG, respectively. To control for changes in the distribution of all revascularization patients across the three severity categories, Panel B considers changes in the within-severity use of CABG and PTCA. Across all three levels, the PTCA rate among the "added"9 revascularization procedures (Column 6) is greater than that for patients revascularized in 1993 (Column 2). For instance, in 1993, 62\% (13\%) of patients with medium (high) severity CAD received PTCA. PTCA, however, accounted for 79\% (36\%) of the incremental medium (high) patients between 1993 and 1995. These results are consistent with the hypothesis of PTCA serving as a stronger substitute for CABG during the mid-1990s.

Figure 3 provides time-series data on the average hospital cost for discharges involving CABG and PTCA. Similar to most administrative databases, SPARCS provides dischargelevel information concerning gross charges, but not costs. To estimate costs, we calculate the

\footnotetext{
${ }^{8} \mathrm{~A}$ vessel is considered "diseased" if it is at least $70 \%$ blocked and a given patient may have between one and four diseased vessels. "Severe" patients are those with blockage of the left ma in trunk (LMT) or at least three diseased vessels; "medium" patients have either two diseased vessels or single-vessel disease in the left anterior descending (LAD) artery; and "mild" patients have single-vessel disease in areas other than the LMT or LAD.

${ }^{9}$ We define "added" procedures as the gap between the number of cases in 1995 and 1993 for a given procedure within a given severity level. The absolute number of "added" procedures presented in Column 5 of Table 1 may be negative and the percentages in Column 6 may thus be negative (though the percentages for any given severity level still sum to 100).
} 
cost-to-charge ratio for each hospital year using data from the Medicare Hospital Cost Reports for the period from 1985 to 1998 . For a given hospital, the cost-to-charge ratio is simply total operating expense divided by gross patient revenues. ${ }^{10}$ All costs are reported in 1985 dollars, using the average CPI for a given year as the deflator.

These data are not adjusted for changes in the severity of the average patient in each category. The dramatic difference in the average costs for CABG and PTCA over time-with that of the former being two-to-three times that of the latter in all years from 1982 to 1998 - thus must be interpreted with caution. Much of this difference may be driven by the fact that CABG tends to be performed on more severe patients. ${ }^{11}$ Accounting for these severity differences is critical when analyzing the cost implications of increased substitution between CABG and PTCA. With these caveats in mind, we note that for both CABG and PTCA, the average cost for the initial hospitalization increases during the second half of the 1980s and is flat during the early 1990s. CABG costs actually begin to decline after 1996, while those for PTCA remain flat.

\section{RESULTS}

${ }^{10}$ This single ratio does not capture the heterogeneity in cost-to-charge ratios across various clinical departments within a given hospital (e.g., the cost-to-charge ratio for cardiac care may be quite different from the average ratio for an entire facility). To the extent that each hospital's composition of low-margin and high-margin services differs, the use of a single cost-to-charge ratio for each facility may bias the comparison of cardiac costs across facilities. Nevertheless, our cost analysis is limited to those hospitals that provide CABG and PTCA. Given the large fixed costs required to establish CABG and PTCA programs (Huckman, 2000), these hospitals are likely to have a relatively high mix of complex patients. As such, one could argue that we are comparing data for hospitals with case mixes that are more homogeneous than those across all hospitals in New York. This homogeneity might mitigate, though will not eliminate, the bias created by the use of hospital-level cost-to-charge ratios. Despite this limitation of cost-to-charge ratios, they have been shown to be preferable to simply using gross charges as a proxy for costs (Newhouse, Cretin, and Witsberger (1989). Meltzer and Chung (2001) provide an extensive discussion of the benefits and limitations of using cost-to-charge ratios for comparisons across hospitals.

${ }^{11}$ As an additional caveat, we emphasize that the costs presented in Figure 3 only cover the initial hospitalization for either CABG or PTCA. As suggested by Hlatky et al. (1997), the costs associated with these 


\section{Changes in Utilization Rates}

The summary evidence presented thus far has certain limitations. In addition to facing potential selection problems, the CSRS and CARS data in Table 1 cover only a short period of time. While Figure 2 does consider changes in CABG and PTCA rates per person, it does not provide evidence as to whether changes in CABG utilization are driven by changes in PTCA use or by some other characteristic of a given area. To address both of these issues, we take advantage of the information on county of patient residence that is available in the SPARCS data and exploit variations in utilization across the different counties of New York.

Table 2 presents the results for the levels regressions. The estimates in Column 1 are based on observations for each county-year from 1982 to 2000 . Due to the aforementioned concerns about data integrity in 1983 and 1984, this regression excludes data for those two years. Though included in the regression, the fixed effects for county and year are not presented in the table. Each interaction term represents a change in the PTCA rate coefficient relative to 198285-the period when the value of the substitution coefficient was at its peak. As noted above, the value of the substitution for any given period - the sum of the base PTCA coefficient and the relevant interaction term-is potentially biased. Nevertheless, the change in this coefficient over time_captured by the interaction terms_-will be unbiased under the assumptions discussed in Section III. These changes increase in absolute magnitude from -0.33 in $1986-88$ to -0.84 in 1998-2000. From the 1989-91 period onward, these changes relative to excluded period of 198285 are statistically significant at either the $5 \%$ or $1 \%$ level.

Column 2 repeats the specification from Column 1 on a subset of the initial sample with observations from 1986 to 2000, the years for which complete payer mix data is available. The 
changes in the interaction terms over time are quite similar in terms of both magnitude and significance to those in Column 1. The excluded time period now becomes the 1986-88 period and the decline in the interaction terms from $1986-88$ to $1998-2000$ is 0.54 , only slightly larger than the decline of 0.51 over the same period in Column 1. Column 3 reveals that the addition of payer mix variables does not substantially affect the coefficients on the interaction terms.

Finally, Column 4 incorporates interactions of the payer mix and age variables with each of the three-year time periods to allow payment systems and age distributions to have time-varying effects of CABG utilization. These controls slightly decrease the absolute magnitude of the interaction terms over time. For example, the change by $1998-2000$ is -0.42 versus the -0.52 figure in Column 3. In addition, the coefficients for the 1989-91 and 1992-94 periods are no longer significant at conventional levels. Nevertheless, the pattern of changes remains monotonic and the changes from 1995 onward are significant at conventional levels. As the most conservative estimates of the change in substitution coefficient over time, our results from Column 4 suggest that, if one assumes that substitution away from CABG accounts for none of the increased PTCA volume in the 1986-88 period, ${ }^{12}$ such substitution accounts for roughly $40 \%$ of the increase in PTCA volume by 1998-2000.

The results from the changes specification (Table 3) mirror those from the levels model. This regression includes observations for all county-periods ending between 1986 and 2000. The excluded interaction term for this regression is that for 1989-1991, the period during which the value of the coefficient is at its peak. Column 1 presents the estimates for a specification without payer variables, Column 2 includes payer variables, and Column 3 adds payer-time and age-time

\footnotetext{
${ }^{12}$ Assuming that the true value of the substitution coefficient in the 1982-1985 period is zero is reasonable given the fact that PTCA was initially used on patients with very mild CAD (Hillis and Rutherford, 1994). It is, therefore, quite plausible that the patients receiving PTCA at this point would not have received CABG in the absence of PTCA.
} 
interactions. The magnitudes and significance of the key interaction terms are stable across the three specifications. As in the levels model, the PTCA rate-time coefficients show a substantial decline during the 1990s, with those changes being significant at the 5\% level for both the 199597 and 1998-2000 periods. Our most conservative estimate of the change from 1989-91 to 19982000 is the -0.32 figure in Column 3. Over the same period, the levels model (Table 2, Column 4) suggests a -0.25 change. These similar figures indicate a dramatic change in the relationship between the utilization rates for CABG and PTCA during the 1990s.

\section{Changes in Cost}

To put the effects of this increased substitution in perspective, we consider the change over time in the net cost of an incremental PTCA. Net cost refers to the cost associated with an additional PTCA less any savings due to the fact that some additional PTCAs represent "foregone" CABG procedures. The change in the coefficient on the PTCA rate indicates the changing mix of treatment substitution and treatment expansion over time.

The SPARCS data provide information about per admission costs, but not costs over time. We thus use the results of Hlatky et al. (1997), who find the average five-year cost for a CABG case to be nearly $\$ 2,700$ greater than that for PTCA for patients with multi-vessel CAD $(\$ 58,889$ for $\mathrm{CABG}$ vs. $\$ 56,225$ for PTCA, $\mathrm{p}<0.05) .{ }^{13}$ They decompose this difference into separate effects for patients with three- and two-vessel disease. Among three-vessel patients, they find no significant difference in the five-year cost of CABG and PTCA. For patients with two-vessel disease, however, the five-year cost of PTCA is roughly $\$ 5,500$ less than that for

\footnotetext{
${ }^{13}$ Hlatky et al. (1997) estimate costs by applying department-specific cost-to-charge ratios from Medicare Cost Reports to charge data. Their results include physician and outpatient costs as well. Due to the absence of department-specific charges or physician charges in the SPARCS data, we are not able to replicate their methodology using the New York data.
} 
PTCA ( $\$ 58,498$ for CABG vs. $\$ 52,930$ for PTCA, $\mathrm{p}<0.05) .{ }^{14}$ Finally, they note that, across both two- and three- vessel patients, the average cost of the initial discharge is roughly $\$ 11,000$ lower for PTCA than for CABG. ${ }^{15}$ This gap narrows, though does not entirely close, during the five year following the initial procedure likely due to the potential for restenosis after PTCA.

Table 4 combines the cost data of Hlatky et al. (1997) with our findings regarding the degree of substitution between the procedures in New York between 1989 and 2000. We choose this timeframe for our analysis because the 1989-91 period is the point at which the estimated value of $\beta$ is at its peak in the changes model. The first column of the table compares the costs associated with 100 incremental PTCAs in 1989-91 to that during the 1998-2000 period using the estimates from the levels model. The decline in $\beta$ over this period -0.25 -implies that $25 \%$ of these incremental PTCAs represent treatment substitution (i.e., cases that would have been treated with CABG in 1989-91), while the remainder results from treatment expansion. The five-year net cost for a PTCA represents the average cost for a PTCA patient less our estimate of the five-year cost for a patient who receives either medical treatment or catheterization without subsequent revascularization. ${ }^{16}$ We find this cost to be approximately $\$ 20,800$ per case. The negative net cost of roughly $\$ 2,700$ attached to each of the substituted procedures reflects the fact that performing PTCA on these patients allows them to avoid a (more expensive) CABG procedure. These results show that while the growth of PTCA has resulted in higher total costs,

\footnotetext{
${ }^{14}$ We note that $71 \%$ of the two- and three-vessel patients receiving PTCA between 1993 and 1995 in New York - the only population for which we can observe CAD severity-had only two-vessel disease. Given the increased use of stents during this period, we would expect this percentage to have been even larger in the pre-1993 period. In checking the results in our sample, we, therefore, emphasize comparison to the findings of Hlatky et al. (1997) with respect to two- rather than three-vessel cases.

${ }^{15}$ This figure is similar to the gap between CABG and PTCA costs found in the New York data (Figure 3).

${ }^{16}$ See note in Table 3 for a more detailed description of this calculation.
} 
the magnitude of this increase has been offset over time by the substitution of PTCA for CABG.

As a result of this substitution, the increase in total costs associated with incremental PTCA

volume fell $11 \%$ (in the levels regression) to $16 \%$ (in the changes regression) between the 1989-

91 and 1998-2000 periods.

The results of Haltky et al. (1997) are based on data from the Bypass Angioplasty

Revascularization Investigation (BARI), a trial of the two revascularization methods that

considered patients with multivessel CAD who underwent either of these procedures between

1988 and 1991 at 18 sites in the United States and Canada (Bypass Angioplasty

Revascularization Investigation [BARI] Investigators, 1996). The time period during which

these procedures were performed preceded the use of stents and other technological

improvements that appear to have increased the initial (i.e., index-admission) costs of PTCA.

Nevertheless, the decreased rate of restenosis associated with stenting suggests that much, if not

all, of this initial cost increase dissipates as one moves further away from the initial admission. ${ }^{17}$

To the extent that stenting reduces the long-term costs of PTCA, it may increase the five-year cost advantage of PTCA relative to CABG identified by Hlatky et al. (1997).

\section{Changes in Outcomes}

Prior to estimating PTCA's implications for productivity, we must determine its effect on outcomes. Given the different clinical profiles of patients who receive PTCA over CABG (i.e,

${ }^{17}$ Cohen et al. (2001) randomized AMI patients to receive either simple PTCA or PTCA with a stent. They found that patients receiving stents had higher costs associated with their index hospital admission ( $\$ 16,959 \mathrm{vs}$. $\$ 15,004$ for PTCA only, $\mathrm{p}<0.001$ ). Using total cost over one year following the index admission, however, this $13 \%$ gap decreased to $5 \%$ ( $\$ 20,571$ for stents vs. $\$ 19,595$ for PTCA only, $\mathrm{p}=0.02$ ). Concurrent with the closing of this gap, stent patients also had a lower rate of repeat revascularization within one year of the index procedure $(13.1 \%$ vs. $22.5 \%$ for PTCA only, $\mathrm{p}<0.001$ ). To our knowledge, no studies have tracked the costs of stenting relative to simple PTCA beyond one year after the index admission. 
substitution) and those who receive it instead of medical treatment (i.e., expansion), we consider separately the impact of PTCA on outcomes for each of these groups.

\section{Treatment Substitution}

As noted above, risk-adjusted mortality likely is an imperfect dimension along which to compare outcomes for CABG and PTCA patients. Nonetheless, mortality is the most common measure used in the clinical literature for this purpose. In Appendix A, we provide estimates of the impact of using PTCA rather than CABG on patient mortality during the 1993-95 period in New York. These results are of limited applicability to our analysis, as they cover only a threeyear period during which PTCA was a relatively mature technology and do not allow us to estimate the impact of PTCA in the years immediately following its introduction into mainstream use. Nevertheless, 1993-95 represents a period during which the substitution of PTCA for CABG appears to have increased, likely due to the increased use of coronary stents.

While we consider these logistic regressions in greater detail in Appendix A, we briefly highlight the key findings. The negative and significant coefficient on the PTCA indicator suggests that—after controlling for numerous clinical determinants of mortality—patients receiving PTCA are less likely to die in the hospital than those receiving CABG. Further, the interaction of the PTCA variable with the calendar-year dummies reveals that this coefficient becomes more negative over the three-year period in the sample. From 1993 to 1995, this decrease is significant, suggesting that the outcomes for PTCA are improving relative to those for $\mathrm{CABG}$ during this period.

Given the limitations of our data, we draw upon the results of randomized trials of PTCA and CABG conducted in the late 1980s and early 1990s to estimate the impact of PTCA's 
diffusion on outcomes. Most of these studies find no significant differences in long-term (i.e., two or more years after index admission) mortality for patients receiving CABG versus PTCA. For example, the Bypass Angioplasty Revascularization Investigation (BARI) trial found that, for non-diabetic patients with multivessel disease, there was no significant difference in the fiveyear mortality for patients randomized to either CABG or PTCA (Chaitman et al., 1997). For multivessel patients with diabetes, those receiving CABG had significantly lower five-year mortality than those receiving PTCA. The Coronary Angioplasty Versus Bypass Revascularization Investigation (CABRI) trial found no significant differences in two-year mortality for multivessel patients randomized to each form of revascularization (CABRI Trial Participants, 1995). Finally, the Medicine, Angioplasty, or Surgery Study (MASS) found no significant differences in five-year mortality for CABG and PTCA in patients with severe single vessel disease in the left anterior descending (LAD) artery (Hueb et al., 1999). These studies, however, are based on patients treated prior to the introduction of stents into mainstream use - an event that likely improved the long-term outcomes of PTCA relative to CABG. Despite this fact, we maintain the assumption that PTCA and CABG yield similar long-term outcomes to ensure that our calculations are not biased toward finding that PTCA increases productivity.

\section{Treatment Expansion}

PTCA's benefit over medical therapy does not appear as a significant decrease in mortality, but rather as an improvement in the quality of life. In particular, patients receiving PTCA were more likely to be relieved of the symptoms of angina—chest pain due to restricted blood flow - than those receiving medical therapy. Parisi, Folland, and Hartigan (1992) find that $64 \%$ of patients randomized to PTCA were free of angina after six months compared to only 
$46 \%$ of those treated medically. This difference of 18 percentage points is significant at the $1 \%$ level.

Expressing this benefit in financial terms requires us to make two assumptions. First, we must determine the utility value, in terms of quality-adjusted life years (QALYs), of living with angina. Most clinical studies of this issue suggest a QALY value of roughly 0.8 for moderate angina (Tengs and Wallace, 2000). That is, the average patient with angina would be willing to trade one year of life with angina for 0.8 years in perfect health. Under this assumption, relieving angina would be valued at $0.2(=1-0.8)$ QALYs per patient-year.

Our second assumption involves assigning a dollar value to a QALY. This amount varies across studies. Viscusi's (1993) survey of the literature suggests that reasonable estimates for the value of life fall in the range of $\$ 3$ million to $\$ 7$ million. Assuming life expectancy of 40 years for the population involved, this range translates into an average value per life-year of $\$ 100,000$ to $\$ 150,000$ (Cutler and Richardson, 1997; Murphy and Topel, 2002). In the interest of keeping our estimates conservative, we also assume a value of $\$ 100,000$ per QALY. Based on the two assumptions above, we determine the average value of being relieved from angina for one year to be $\$ 20,000$ per patient (0.2 QALY x \$100,000/QALY).

\section{Productivity Implications}

Table 5 combines the effects of both treatment expansion and substitution to estimate the overall impact of PTCA on medical productivity in the year 2000 relative to 1989-91. Consistent with the approach in Table 4, we consider the impact of 100 additional PTCAs in the 1998-2000 period relative to the $1989-1991$ period. Columns 1 and 2 provide the results using the substitution percentages from the levels and changes regressions, respectively. As noted above, 
we credit PTCA only with the benefits of reduced angina for treatment expansion patients (i.e., any benefit in terms of outcomes for treatment substitution patients is not factored into this analysis). Nevertheless, we do include all of the additional costs associated with the use of PTCA.

The first row in the "Benefit of Treatment Expansion" section shows the number of patients who are relieved of angina due to the use of PTCA instead of medical therapy. In accordance with the findings of Parisi, Folland, and Hartigan (1992) concerning angina relief, this figure represents $18 \%$ of the treatment expansion patients. Assuming an average survival of 10 years following PTCA ${ }^{18}$, an annual benefit of $\$ 20,000$ per patient relieved of angina, and no incremental gain due to treatment substitution, we calculate the total benefit of 100 PTCAs to be between $\$ 2.4$ million and \$2.7 million. From this figure, we subtract the total cost of these additional PTCAs, as reported in Table 4. The resulting net benefit is between $\$ 19,000$ and $\$ 22,000$ per additional PTCA.

The above result is sensitive to our assumptions concerning the average survival of a PTCA patient. PTCA, however, would still have a positive net benefit even if we were to lower the average survival from 10 to two years while holding the benefit per patient-year of angina relief at $\$ 20,000$. Similarly, if we were to hold the average survival constant at 10 years, we could lower the benefit per patient-year to roughly \$3,900 (roughly 0.04 QALY) and still maintain a positive net benefit of PTCA.

We consider the robustness of the productivity results using methods other than QALY analysis for valuing the benefits of angina relief. One such approach is to calculate the direct

\footnotetext{
${ }^{18}$ We use 10 years as an estimate of the average survival following PTCA. The meta-analysis of Eagle et al. (1999) from the United States, Europe, and New Zealand finds a 74\% survival rate for CABG after 10 years. Given the similarity in five-year survival for CABG and PTCA, we assume that an estimated average survival of 10 years is reasonable for PTCA.
} 
medical and non-medical costs associated with angina. Using data on over 400 angina patients from Sweden, Andersson and Kartman (1995) find the average annual direct medical cost for angina patients to be 40,052 Swedish kronor (approximately $\$ 5,600$ in 1995) and the nonmedical cost (e.g., value of time spent seeking treatment, value of production lost due to reduction in work hours) to be of similar magnitude at 38,225 kronor (approximately $\$ 5,300$ ). The average annual benefit of angina relief is thus $\$ 10,900$. This amount, however, includes roughly $\$ 700$ on average for CABG or PTCA, which should be subtracted from the annual benefit of angina relief for treatment expans ion patients who, by definition, would not otherwise receive these therapies. After this adjustment, the average annual benefit of angina relief is roughly $\$ 10,200$, a figure that is substantially higher than the $\$ 3,900$ minimum benefit required for PTCA to improve productivity in our base calculation. Further, this $\$ 10,200$ amount excludes benefits associated with any improvements in quality of life that are not captured by reductions in medical or non- medical costs.

Table 5 presents the net benefit associated with PTCA at a point in time (i.e., the year 2000) when the technology was relatively mature. It is likely, however, that the benefits of PTCA—in terms of both angina relief and substitution for CABG—-that were present by 2000 were either non-existent or substantially smaller immediately after its introduction in the early 1980s. We examine the flow of benefits and costs over time in Figure 4, where we present the cumulative net benefit per PTCA for each year from 1982 to 2000. To calculate this figure for a given year, we divide the real cumulative net benefit since 1982 (i.e., cumulative benefit minus cumulative cost) by the cumulative number of PTCA discharges as of the end of the year. These net benefit figures are based on the costs in 1995 dollars used in Hlatky et al. (1997) and are discounted using a $3 \%$ real interest rate. Table B1 includes detail on the intermediate steps used 
to calculate the annual amounts plotted in Figure 4. These amounts appear in the final column of the table.

We note several additional assumptions used in calculating these figures. First, our net benefit calculations do not include the fixed costs associated with developing PTCA (e.g., the costs of inventing the initial technology). Nonetheless, the results on the total cumulative net benefit of PTCA in New York (Table B1) suggest that by 1992—-ten years after PTCA's introduction in New York-the cumulative benefit generated from PTCA in New York alone would have been sufficient to justify more than $\$ 1.3$ billion of fixed costs associated with the technology's development. If one were to add the cumulative benefits generated in other states — or in other countries_- where the use of PTCA was increasing during this time, a significantly higher level of fixed costs could be supported. While it is difficult to estimate the fixed costs for the development of PTCA, it is likely that the time flow of cumulative benefitsespecially on a nationwide or international basis - is sufficient to suggest that the technique improved medical productivity.

Second, we assume that the level of angina relief for treatment expansion patients increases linearly from $0 \%$ in 1982 to18\% in 1992 - the year in which Parisi, Folland, and Hartigan (1992) published their findings concerning this benefit of PTCA. By keeping the level of angina relief constant at $18 \%$ through 2000 , we make the conservative assumption that PTCA's outcomes with respect to angina did not improve after 1992. Finally, we use the levels coefficients from Column 4 of Table 2 to obtain the $18 \%$ and $25 \%$ substitution percentages for the 1995-97 and 1998-2000 periods, respectively. Prior to 1995, we assume no cost savings due to substitution, as the coefficients in these periods are not significantly different from those in 1989-91. 
The total benefit of PTCA expansion in New York is calculated as the value of the 0.2 QALY improvement associated with the incremental relief of angina for treatment expansion patients. The total cost column represents the expenditure on additional PTCAs less any savings due to substitution away from CABG. The cumulative net benefit column suggests that the “payback" point for PTCA occurred at some point in 1986. This value increases steadily to value of roughly $\$ 23,800$ in 1994 and then begins to decline slightly once we allow for some degree of substitution in the later 1990s.

As suggested in Table B1, CABG substitution thus has two counteracting effects on our productivity calculations. Most directly, it decreases total cost, as PTCA is cheaper than CABG. By reducing the percentage of cases that are due to treatment expansion, however, it decreases the proportion of new patients who receive incremental angina relief. The pattern in the perPTCA cumulative benefit thus reflects the contribution of incremental angina relief relative to substitution-related cost savings in determining the effects of expanded PTCA use on productivity.

To examine the sensitivity of these results, we repeated this analysis using even more conservative assumptions regarding the phase-in of benefits related to angina relief. Specifically, we assumed that the benefits of angina relief are phased-in only during the five, rather than ten, years prior to 1992. The slope of the phase-in is thus steeper than in the base case, but the point at which benefit begins to accrue is pushed back five years to 1988. Even under these more conservative assumptions, the productivity benefit associated with PTCA's expansion is substantial. The payback year is 1990, and the cumulative benefit per PTCA hits a maximum value of $\$ 19,800$ in 1998 before beginning to decline slightly thereafter. 


\section{DISCUSSION}

Our analysis yields several conclusions. With respect to total costs, we find that an assessment of PTCA's effects based solely on the first decade of its use yields a substantially different result than one — such as ours - that considers the entire life of the technology to date. Specifically, the growth of PTCA in the 1980s occurred predominantly through treatment expansion and was accompanied by little offset in the use of CABG and thus large increases in the overall cost of care. By the mid-1990s, however, PTCA's outcomes improved and it began to serve as a stronger substitute for $\mathrm{CABG}$ such that by the end of the decade, between $25 \%$ and $35 \%$ of new PTCA procedures were substitutes for CABG. Although total costs were higher due to the growth of PTCA, this increase was offset by between $10 \%$ and $20 \%$ between $1989-91$ and 1998-2000 due to substitution of PTCA for CABG. By the metric of costs, the diffusion of a new technology increases spending - rapidly at first as new technology treats those who previously went without, and less rapidly over time as technology substitutes more for those with more expensive existing treatments.

When we take account of quality, our results suggest that the diffusion of PTCA is a quality improvement. Among those receiving PTCA who would have formerly been managed medically, the benefits in lower angina seem to be greater than the added expense. Further, we present initial results in Appendix A suggesting that the substitution of PTCA for CABG-at least during the mid-1990s_ - appears to have improved the quality of outcomes for revascularization patients. This latter result must be qualified by the fact that is based on data from a period of time_-1993 to 1995-during which PTCA was a relatively mature technique that was being improved by technological advancement. In addition, this analysis is limited to 
in-hospital mortality. Nonetheless, even in the absence of any quality improvements for substitution patients, the diffusion of PTCA appears to have increased medical productivity.

We conclude with a note concerning the scope of this analysis. The utilization rates for New York may differ substantially from those for the rest of the United States. For example, Guadagnoli et al. (1995) examine Medicare patients in 1990 and find that the rate of CABG within 90 days of admission was $15 \%$ in Texas versus $13 \%$ in New York. In terms of PTCA, the rate in Texas (15\%) was more than double that in New York (7\%). Further, New York's adjusted rates of CABG and PTCA for Medicare enrollees during 1995 and 1996 were below both the average and median rates across all 50 states (Center for Evaluative and Clinical Sciences, 1999). While the cause of these relatively low rates is not clear, candidate explanations included differences in medical practice patterns or New York's relatively stringent certificate-of-need (CON) regulation for the adoption of new technologies by hospitals.

Expanding this analysis to other states would allow us to test the robustness of our findings in settings characterized by different regulatory structures and patterns of medical practice. In particular, we would like to consider a state, such as California, in which hospitals are subject to less stringent restrictions concerning the adoption of new technologies. Finally, while our study focuses on cardiac procedures, we believe that our findings can be applied to other medical innovations that, as of their date of introduction, are characterized by uncertainty with respect to their ultimate costs and benefits. In such settings, it appears that an innovation's impact on productivity may depend on the length of the horizon over which such effects are measured. 


\section{APPENDIX A}

Given the limitations of in-hospital mortality as a measure of the relative outcomes for PTCA and CABG patients, we do not rely on it for our productivity calculations. Nevertheless, the impact of PTCA on mortality merits further discussion.

Ideally, one would hope to regress the risk-adjusted mortality rate for an exogenously determined population that is likely to receive either PTCA or CABG (e.g., AMI patients) on indicators for the use of PTCA, CABG, or medical treatment and a serie s of controls for patient severity. While the SPARCS data covers all AMI patients, it does not provide the detailed clinical data available from the NYSDOH. The CSRS and CARS data, while providing more clinical information than SPARCS, only cover patient s receiving CABG or PTCA, not all AMI patients. We thus do not have access to the data that would be required to perform the desired analysis. Further, many individuals with a diagnosis of AMI do not actually undergo PTCA or CABG. As a result of the numerous factors—both within and outside of the hospital— that may cause mortality for an AMI patient, it represents a noisy measure of PTCA's impact on outcomes. $^{19}$

Using the CSRS and CARS data, we are able to consider the impact of using PTCA rather than $\mathrm{CABG}$ conditional on a patient receiving either of these procedures in New York between 1993 and 1995. For each patient, CSRS and CARS collects data on clinical risk factors including measures of blood flow (e.g., ejection fraction), history of cardiac disease and procedures, smoking habits, and the presence of other diseases such as diabetes and renal failure.

${ }^{19}$ McClellan and Staiger (1999) note that in-hospital mortality for AMI patients may be noisy due to its relatively low occurrence and the wealth of factors that may cause it. They present a methodology for "filtering" risk-adjusted mortality rates (RAMRs) that are observed in Medicare claims data over relatively small populations (e.g., patients at a single hospital) during relatively short time periods (e.g., one year). 
While there likely remains some degree of unobserved heterogeneity across patients in these data, this population likely is more homogeneous along these unobserved dimensions than the larger universe of AMI candidates.

We estimate a logistic regression with the dependent variable, $M O R T_{i}$, being equal to one if an individual died within the hospital and zero otherwise. The form of this equation is:

$$
\ln \left(\frac{\operatorname{Pr}\left(M O R T_{i}=1 \mid x_{i}\right)}{1-\operatorname{Pr}\left(M O R T_{i}=1 \mid x_{i}\right)}\right)=\mu_{0}+\mu_{1}\left(P T C A_{i} * Y E A R_{i}\right)+\mu_{2} C_{i}+?_{i}
$$

where $v_{i}$ is distributed extreme value. The key independent variables are the interactions of $P T C A_{i}$ - an indicator equal to one (zero) if a patient received PTCA (CABG) as the initial form of revascularization—with dummy variables for year of admission. These interactions capture the degree to which the performance of PTCA relative to CABG changes over the three-year period studied. $C_{i}$ is a vector of control variables that includes indicators for each year, linear and quadratic terms for patient age, and information on over 30 clinical risk factors for each patient. $^{20}$ The above specification is run both with and without hospital-specific dummy variables, with the goal of the latter regression being to control for time-invariant factors (e.g., particular surgeons, cardiologists, or technicians) that may be correlated with outcomes at a given hospital.

The timeframe of this analysis does not allow us to capture PTCA's effect on outcomes in the years immediately following its introduction. Nevertheless, it does enable us to measure the technology's impact after the technology has been in place for several years at a given

\footnotetext{
${ }^{20}$ A complete list of these clinical covariates appears in the note at the bottom of Table A1.
} 
hospital. That is, we consider whether—as PTCA use approaches an "equilibrium" level of utilization—the outcomes for patients undergoing revascularization improves.

Table A1 presents the results for the logistic regression measuring the impact of PTCA on revascularization outcomes. Columns 1 and 2 provide estimates for versions of the model with and without hospital fixed effects, respectively. The results for both models are similar, so we address them in a single discussion. The coefficient on the PTCA indicator is negative and highly significant, suggesting that—after controlling for numerous clinical determinants of mortality - patients receiving PTCA are less likely to die in the hospital than those receiving CABG. That is, the use of PTCA appears to be associated with improved in-hospital outcomes relative to CABG. Further, the interaction of the PTCA variable with the calendar-year dummies reveals that this negative coefficient decreases over the three-year period in the sample. From 1993 to 1995, this decrease is significant, suggesting that the outcomes for PTCA are improving relative to those for $\mathrm{CABG}$ during this period. Though a causal link cannot be confirmed, this finding is consistent with the claim that the technological development of PTCA (e.g., increased and improved use of stents) led to improved outcomes using the procedure.

It is possible that the positive coefficient on the CABG indicator is simply due to unobserved heterogeneity in patient severity. We believe that the extensive array of clinical covariates included in these regressions should mitigate concerns about this bias. It thus seems unlikely that unobservables explain all of the effect we identify. As an additional qualification, we reiterate that the CSRS and CARS data only track in-hospital mortality. To the extent that post-hospital mortality differs in a manner that is systematically related to our observed variables, in-hospital mortality may provide a biased measure of overall death rates. Finally, as mentioned above, mortality is only one of several relevant quality measures in this setting. 
Others include post-procedure pain, complications, and functional ability. Even with these caveats, however, we note that the State of New York feels that this mortality data is meaningful enough to use it to compare outcomes for hospitals and individual physicians in its public report cards on cardiac care (New York State Department of Health, 1998). 


\section{Table A1: Logistic Regression of Mortality for Revascularization (CABG or PTCA) Patients}

\begin{tabular}{|c|c|c|}
\hline \multirow[b]{2}{*}{ Did Patient Receive PTCA? } & \multicolumn{2}{|c|}{ Dependent Variable: In-Hospital Mortality? } \\
\hline & $\begin{array}{l}-0.560 \text { *** } \\
(0.112)\end{array}$ & $\begin{array}{l}-0.509 \\
(0.113)\end{array}$ \\
\hline Year $=1994 ?$ & $\begin{array}{r}0.017 \\
(0.074)\end{array}$ & $\begin{array}{r}0.013 \\
(0.074)\end{array}$ \\
\hline Year $=1995 ?$ & $\begin{array}{r}0.077 \\
(0.073)\end{array}$ & $\begin{array}{r}0.061 \\
(0.073)\end{array}$ \\
\hline Did Patient Receive PTCA $?$ x Year $=1994 ?$ & $\begin{array}{r}-0.159 \\
(0.141)\end{array}$ & $\begin{array}{r}-0.166 \\
(0.141)\end{array}$ \\
\hline Did Patient Receive PTCA $?$ x Year $=1995 ?$ & $\begin{array}{l}-0.300 * * \\
(0.136)\end{array}$ & $\begin{array}{l}-0.311^{* *} \\
(0.137)\end{array}$ \\
\hline Constant & $\begin{array}{l}-5.468 \text { *** } \\
(0.868)\end{array}$ & $\begin{array}{l}-5.929 * * * \\
(0.890)\end{array}$ \\
\hline $\begin{array}{l}\text { Pre-Procedure Risk Factors? } \\
\text { Hospital Dummy Variables? }\end{array}$ & $\begin{array}{l}\text { Yes } \\
\text { No }\end{array}$ & $\begin{array}{l}\text { Yes } \\
\text { Yes }\end{array}$ \\
\hline $\begin{array}{l}\text { Observations } \\
c\end{array}$ & $\begin{array}{r}109,323 \\
0.864\end{array}$ & $\begin{array}{r}109,323 \\
0.867\end{array}$ \\
\hline
\end{tabular}

Note: "**, ${ }^{* *}$ denote statistical significance at the $10 \%, 5 \%$, and $1 \%$ levels, respectively. Records for patients who received CABG on an emergency basis following PTCA or who received CABG during an admission in which PTCA was also performed were excluded, as these individuals are considered PTCA patients. Regressions also include the following pre-procedure risk factors for each patient: age, age squared, gender, race, body surface area, CCS functional class for angina, and indicators for any previous MI, MI within previous 24 hours, MI within previous one week, transmural MI, stroke, cerebrovascular disease, narrowing in aortoiliac vessel, narrowing in femoral/popliteal vessel, hemodynamic instability, shock, hypertension, IV nitroglycerin within previous 24 hours, left ventricular hypertrophy, malignant ventricular arrhythmia, chronic obstructive pulmonary disease, diabetes, immune system deficiency, pre-operative intra-aortic balloon pump, previous PTCA, thrombolytic therapy within previous seven days, smoking history within previous two weeks, congestive heart failure, renal failure, ejection fraction less than $20 \%$, eiection fraction $20-29 \%$, and eiection fraction $30-39 \%$.

In addition, the regression includes indicators for the presence of blockage in the following locations: LMT, proximal LAD, mid/dist $L A D, R C A$, or $L C X$. The New York State Department of Health provides the following caveat with respect to the use of the indicator for chronic obstructive pulmonary disease (COPD) for risk adjustment: "Prior to 1993, the definition used for COPD was considered subjective, and irregular frequency distributions across institutions were noted. The definition was changed in 1993 to include documentation of objective clinical criteria. However, the wide range in COPD rates reported across hospitals remains, presumably due to practice patterns among various providers with regard to utilizing objective testing for COPD." 


\section{APPENDIX B}

Table B1: Annual Flows of Net Benefits From PTCA Diffusion

\begin{tabular}{|c|c|c|c|c|c|c|c|c|c|c|c|c|c|}
\hline \multirow{3}{*}{$\begin{array}{l}\text { Year } \\
1982\end{array}$} & \multirow{3}{*}{$\begin{array}{c}\text { Percent Angina } \\
\text { Relief for Treatment } \\
\text { Expansion Patients } \\
0 \%\end{array}$} & \multirow{3}{*}{$\begin{array}{c}\text { Treatment } \\
\text { Substitution } \\
\text { Percentage }^{c} \\
0 \%\end{array}$} & \multirow{3}{*}{$\begin{array}{r}\text { Total PTCA } \\
\text { Discharges for } \\
\text { NY Residents } \\
379\end{array}$} & \multicolumn{10}{|c|}{ Amounts in $\$ 000 \mathrm{~s}^{d}$} \\
\hline & & & & \multicolumn{2}{|c|}{$\begin{array}{c}\text { Total Benefit } \\
\text { (Angina Relief) }^{\mathrm{e}} \\
\end{array}$} & \multicolumn{2}{|c|}{$\begin{array}{l}\text { Total Cost } \\
\text { (Including } \\
\text { Substitution } \\
\text { Savings) } \\
\end{array}$} & \multicolumn{2}{|c|}{ Net Benefit } & \multicolumn{2}{|c|}{$\begin{array}{c}\text { Cumulative Net } \\
\text { Benefit } \\
\end{array}$} & \multicolumn{2}{|c|}{$\begin{array}{c}\text { Cumulative } \\
\text { Net } \\
\text { Benefit/PTCA }\end{array}$} \\
\hline & & & & $\$$ & - & $\$$ & 4,381 & $\$$ & $(4,381)$ & $\$$ & $(4,381)$ & $\$$ & $(11.6)$ \\
\hline $1983^{a}$ & $2 \%$ & $0 \%$ & 1,081 & $\$$ & 5,547 & $\$$ & 12,129 & $\$$ & $(6,582)$ & $\$$ & $(10,964)$ & $\$$ & $(7.5)$ \\
\hline $1984^{a}$ & $4 \%$ & $0 \%$ & 1,782 & $\$$ & 17,764 & $\$$ & 19,422 & $\$$ & $(1,658)$ & $\$$ & $(12,621)$ & $\$$ & (3.9) \\
\hline 1985 & $5 \%$ & $0 \%$ & 2,484 & $\$$ & 36,054 & $\$$ & 26,279 & $\$$ & 9,775 & $\$$ & $(2,847)$ & $\$$ & $(0.5)$ \\
\hline 1986 & $7 \%$ & $0 \%$ & 3,794 & $\$$ & 71,284 & $\$$ & 38,969 & $\$$ & 32,316 & $\$$ & 29,469 & $\$$ & 3.1 \\
\hline 1987 & $9 \%$ & $0 \%$ & 5,584 & $\$$ & 127,326 & $\$$ & 55,684 & $\$$ & 71,642 & $\$$ & 101,111 & $\$$ & 6.7 \\
\hline 1988 & $11 \%$ & $0 \%$ & 6,783 & $\$$ & 180,192 & $\$$ & 65,670 & $\$$ & 114,522 & $\$$ & 215,633 & $\$$ & 9.9 \\
\hline 1989 & $13 \%$ & $0 \%$ & 7,622 & $\$$ & 229,347 & $\$$ & 71,644 & $\$$ & 157,703 & $\$$ & 373,336 & $\$$ & 12.7 \\
\hline 1990 & $14 \%$ & $0 \%$ & 9,497 & $\$$ & 317,077 & $\$$ & 86,668 & $\$$ & 230,409 & $\$$ & 603,745 & $\$$ & 15.5 \\
\hline 1991 & $16 \%$ & $0 \%$ & 11,526 & $\$$ & 420,313 & $\$$ & 102,120 & $\$$ & 318,192 & $\$$ & 921,938 & $\$$ & 18.2 \\
\hline 1992 & $18 \%$ & $0 \%$ & 14,183 & $\$$ & 557,933 & $\$$ & 122,001 & $\$$ & 435,932 & $\$$ & $1,357,870$ & $\$$ & 21.0 \\
\hline 1993 & $18 \%$ & $0 \%$ & 15,716 & $\$$ & 600,232 & $\$$ & 131,251 & $\$$ & 468,981 & $\$$ & $1,826,851$ & $\$$ & 22.7 \\
\hline 1994 & $18 \%$ & $0 \%$ & 16,333 & $\$$ & 605,628 & $\$$ & 132,431 & $\$$ & 473,197 & $\$$ & $2,300,048$ & $\$$ & 23.8 \\
\hline 1995 & $18 \%$ & $18 \%$ & 19,347 & $\$$ & 571,123 & $\$$ & 115,608 & $\$$ & 455,515 & $\$$ & $2,755,563$ & $\$$ & 23.7 \\
\hline 1996 & $18 \%$ & $18 \%$ & 23,295 & $\$$ & 667,639 & $\$$ & 135,145 & $\$$ & 532,494 & $\$$ & $3,288,057$ & $\$$ & 23.6 \\
\hline 1997 & $18 \%$ & $18 \%$ & 26,638 & $\$$ & 741,214 & $\$$ & 150,039 & $\$$ & 591,175 & $\$$ & $3,879,232$ & $\$$ & 23.4 \\
\hline 1998 & $18 \%$ & $25 \%$ & 30,094 & $\$$ & 743,587 & $\$$ & 144,256 & $\$$ & 599,331 & $\$$ & $4,478,563$ & $\$$ & 22.8 \\
\hline 1999 & $18 \%$ & $25 \%$ & 31,872 & $\$$ & 764,582 & $\$$ & 148,329 & $\$$ & 616,253 & $\$$ & $5,094,817$ & $\$$ & 22.3 \\
\hline 2000 & $18 \%$ & $25 \%$ & 32,928 & $\$$ & 766,908 & $\$$ & 148,780 & $\$$ & 618,127 & $\$$ & $5,712,944$ & $\$$ & 21.9 \\
\hline
\end{tabular}

a Data on number of PTCA discharges is based on linear interpolation using actual SPARCS figures from 1982 and 1985.

${ }^{b}$ Assumes linear increase in percent angina relief to the $18 \%$ figure identified by Parisi, Folland, and Hartigan (1992) and no subsequent improvements through 2000.

${ }^{c}$ Based on coefficients in Column 4 of Table 2.

${ }^{d}$ All amounts are based on the PTCA and CABG costs in 1995 dollars from Hlatky et al. (1997), which are then discounted at a real interest rate of 3\%.

${ }^{e}$ Assumes QALY increase of 0.2 for angina relief, a QALY value of $\$ 100,000$, and and average of 10 years of angina-free survival. 


\section{REFERENCES}

Andersson, F., Kartman, B., 1995. The cost of angina pectoris in Sweden. PharmacoEconomics $8(3), 233-244$.

Berndt, E., Morrison, C., 1995. High-tech capital formation and economic performance in U.S. manufacturing industries: An exploratory analysis. Journal of Econometrics 65(1), 9-43.

Bohmer, R., Christensen, C., Kenagy, J., 2000. Will disruptive innovations cure health care? Harvard Business Review 78(5), 102-112.

Bypass Angioplasty Revascularization Investigation (BARI) Investigators, 1996. Comparison of coronary bypass surgery with angioplasty in patients with multivessel disease. New England Journal of Medicine 335(4), 211-225.

CABRI Trial Participants, 1995. First-year results of CABRI (Coronary Angioplasty Versus Bypass Revascularization Investigation). Lancet 346(8984), 1179-1184.

Center for Evaluative and Clinical Sciences, 1999. Dartmouth atlas of health care in the United States. http://www.dartmouthatlas.org/tables/99table5.php.

Chaitman, B., Rosen, A., Williams, D., Bourassa, M., Aguirre, F., Pitt, B., Rautaharju, P., Rogers, W., Sharaf, B., Attubato, M., Hardison, R., Srivatsa, S., Kouchoukos, N., Stocke, K., Sopko, G., Detre, K., Frye, R., 1997. Myocardial infarction and cardiac mortality in the Bypass Angioplasty Revascularization Investigation (BARI) Randomized Trial. Circulation 96(7), 21622170 .

Cohen, D., Taira, D., Berezin, R., Cox, D., Morice, M., Stone, G., Grines, C., 2001. Costeffectiveness of coronary stenting in acute myocardial infarction: Results from the Stent Primary Angioplasty in Myocardial Infarction (Stent-PAMI) trial. Circulation 104(25), 3039-3045.

Cutler, D., McClellan, M., 1998. What is technological change? in: Wise,D. (ed.), Inquiries in the economics of aging. University of Chicago Press, Chicago, IL.

Cutler, D., McClellan M., 2001. Is technological change in medicine worth it? Health Affairs 20(5), 11-29.

Cutler, D., Richardson, E., 1997. Measuring the health of the US population. Brookings papers on economic activity, microeconomics 1997, 217-271.

Eagle, K., Guyton, R., Davidoff, R., Ewy, G., Fonger, J., Gardner, T., Gott, J., Herrmann, H., Marlow, R., Nugent, W., O’Connor, G., Orszulak, T., Rieselbach, R., Winters, W., Yusuf, S., 1999. ACC/AHA guidelines for coronary artery bypass graft surgery: Executive summary and recommendations. Circulation 100(13), 1464-1480. 
Eisenberg, J., Schwartz, J., McCaslin, F., Kaufman, R., Glick, H., Kroch, E., 1989. Substituting diagnostic services: New tests only partly replace older ones. Journal of the American Medical Association 262(9), 1196-1200.

Farley, D., Ozminkowski, R., 1992. "Volume-outcome relationships and inhospital mortality: The effect of changes in volume over time. Medical Care 30(1), 77-94.

Fuchs, V., 1986. The health economy. Harvard University Press, Cambridge, MA.

Garber, A., 1994. Can technology assessment control health spending? Health Affairs 13(3), 115-126.

Gelijns, A., Rosenberg, N., 1994. The dynamics of technological change in medicine. Health Affairs 13(3), 28-46.

Guadagnoli, E., Hauptma n, P., Ayanian, J., Pashos, C., McNeil, B., Cleary, P., 1995. Variation in the use of cardiac procedures after acute myocardial infarction. New England Journal of Medicine 333(9), 573-578.

Hannan, E., Kilburn, H., Bernard, H., O’Donnell, J., Lukacik, G., Shields, E., 1991. Coronary artery bypass graft surgery: The relationship between inhospital mortality rate and surgical volume after controlling for clinical risk factors. Medical Care 29(11), 1094-1107.

Hannan, E., Racz, M., Ryan, T., McCallister, B., Johnson, L., Arani, D., Guerci, A. Sosa, J., Topol, E., 1997. Coronary angioplasty volume-outcome relationships for hospitals and cardiologists. Journal of American Medical Association 277(11), 892-898.

Hillis, L. D., Rutherford, J., 1994. Coronary angioplasty compared with bypass grafting. New England Journal of Medicine 331(16), 1086-1087.

Hlatky, M., Rogers, W., Johnstone, I., Boothroyd, D., Brooks, M., Pitt, B., Reeder, G., Ryan, T., Smith, H., Whitlow, P., Wiens, R., Mark, D., Rosen, A., Detre, K., Frye, R., 1997. Medical care costs and the quality of life after randomization to coronary angioplasty or coronary bypass surgery. New England Journal of Medicine 336(2), 92-99.

Ho, V., 2000. Evolution of the volume-outcome relation for hospitals performing coronary angioplasty. Circulation 101(15), 1806-1811.

Huckman, R., 2000. Hospital consolidation and the delivery of cardiac care. Mimeograph.

Hueb, W., Soares, P., de Oliveira, S., Arie, S., Cardoso, R., Wajsbrot, D., Cesar, L., Jatene, A., Ramires, J., 1999. Five-year follow-up of the Medicine, Angioplasty, or Surgery Study (MASS): A prospective, randomized trial of medical therapy, balloon angioplasty, or bypass surgery for single proximal left anterior descending coronary artery stenosis. Circulation 100(19), II-107-II113. 
Legorreta, A., Silber, J., Constantino, G., Kobylinski, R., Zatz, S., 1993. Increased cholecystectomy rate after the introduction of laparoscopic cholecystectomy. Journal of the American Medical Association 270(12), 1429-1432.

Luft, H., Bunker, J., Enthoven, A., 1979. Should operations be regionalized? The empirical relation between surgical volume and mortality. New England Journal of Medicine 301(25), 1364-1369.

Luft, H., Hunt, S., Maerki, S., 1987. The volume-outcome relationship: Practice-makes-perfect or selective-referral patterns? Health Services Research 22(2), 157-182.

Meltzer, D., Chung, J., 2001. Effects of competition under prospective payment on hospital costs among high and low cost admissions: Evidence from California, 1983-1993. NBER Working Paper 8069.

McClellan, M., Staiger, D., 1999. The quality of health care providers. NBER Working Paper 7327.

Murphy, K., Topel, R., 2002. The economic value of medical research. in: Murphy, K. and Topel, R. (eds.), The value of medical research. University of Chicago Press, Chicago, IL.

Newhouse, J., 1992. Medical care costs: How much welfare loss? Journal of Economic Perspectives 6(3), 3-21.

Newhouse, J., Cretin, S., Witsberger, C., 1989. Predicting hospital accounting costs. Health Care Financing Review 11(1), 25-33.

New York State Department of Health, 1998. Coronary artery bypass surgery in New York state: 1994-1996. New York State Department of Health, Albany, NY.

Parisi, A., Folland, E., Hartigan, P., 1992. A comparison of angioplasty with medical therapy in the treatment of single-vessel coronary artery disease. New England Journal of Medicine 326(1), 10-16.

Serruys, P., van Hout, B., Bonnier, H., Legrand, V., Garcia, E., Macaya, C., Sousa, E., van der Giessen, W., Colombo, A., Seabra-Gomes, R., Kiemeneji, F., Ruygrok, P., Ormiston, J., Emanuelsson, H., Fajadet, J., Haude, M., Klugmann, S., Morel, M., 1998. Randomised comparison of implantation of heparin-coated stents with balloon angioplasty in selected patients with coronary artery disease. Lancet 352(9129), 673-681.

Showstack, J., Rosenfeld, K., Garnick, D., Luft, H., Schaffarzick, R., Fowles, J., 1987. Association of volume with outcome of coronary artery bypass graft surgery: Scheduled vs. nonscheduled operations. Journal of the American Medical Association 257(6), 785-789.

Tengs, T., Wallace, A., 2000. One thousand health-related quality-of-life estimates. Medical Care 38(6), 583-637. 
Viscusi, W. K., 1993. The value of risks to life and health. Journal of Economic Literature 31(4), 1912-1946.

Weisbrod, B., 1991. The health care quadrilemma: An essay on technological change, insurance, quality of care, and cost containment. Journal of Economic Literature 29(2), 523-552.

Williams, D., Holubkov, R., Yeh, W., Bourassa, M., Al-Bassam, M., Block, P., Coady, P., Cohen, H., Cowley, M., Dorros, G., Faxon, D., Holmes, D., Jacobs, A., Kelsey, S., King, S., Myler, R., Slater, J., Stanek, V., Vlachos, H., Detre, K., 2000. Percutaneous coronary intervention in the current era compared with 1985-86: The National Heart, Lung, and Blood Institute Registries. Circulation 102(24), 2945-2951. 
Figure 1: Procedure Rates for CABG and PTCA in New York State, 1982-2000

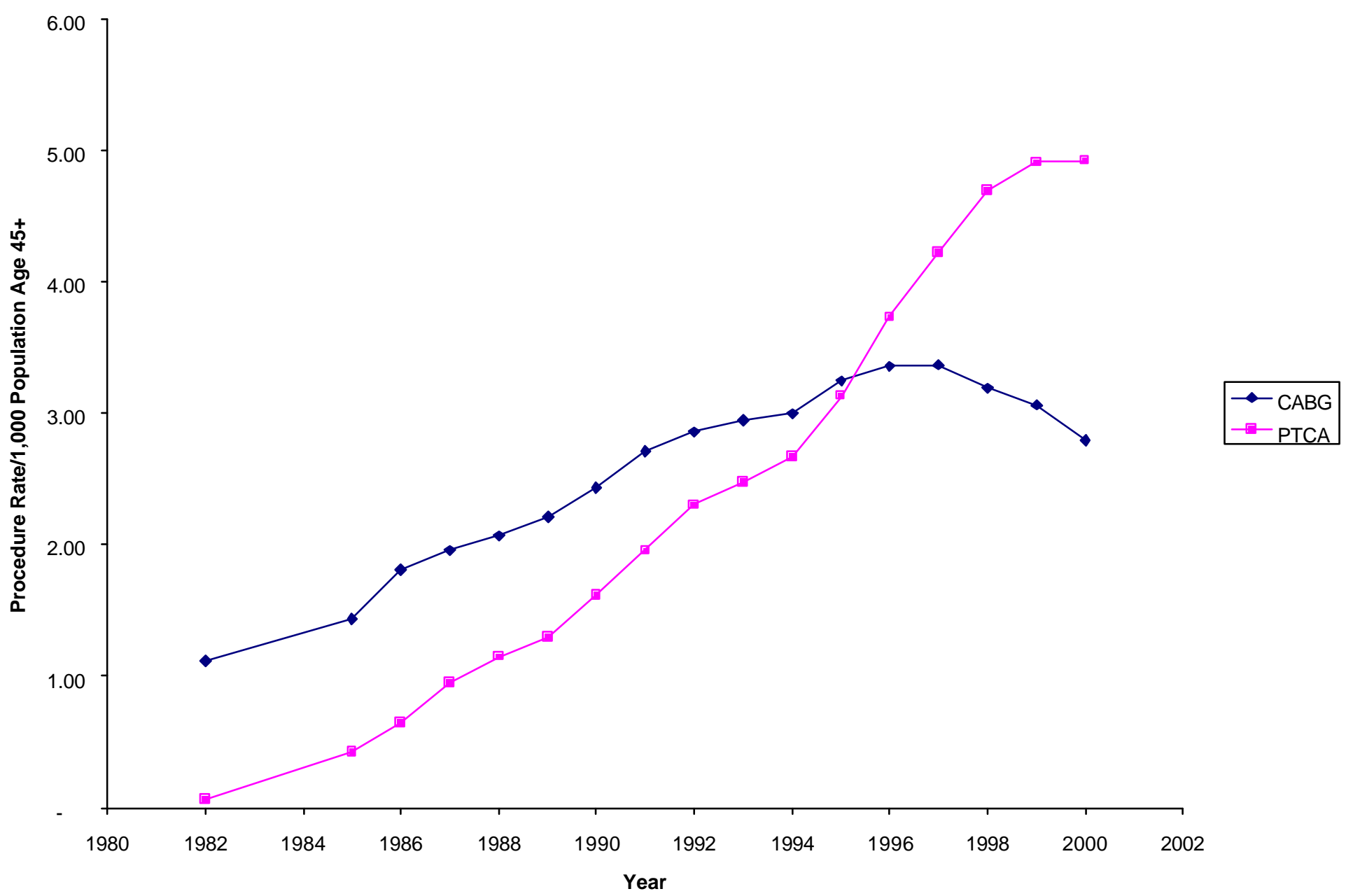

Source: SPARCS Database, 1982-2000. 
Figure 2: Comparison of Changes in CABG and PTCA Rates for Selected Time Periods (County-Level Observations)
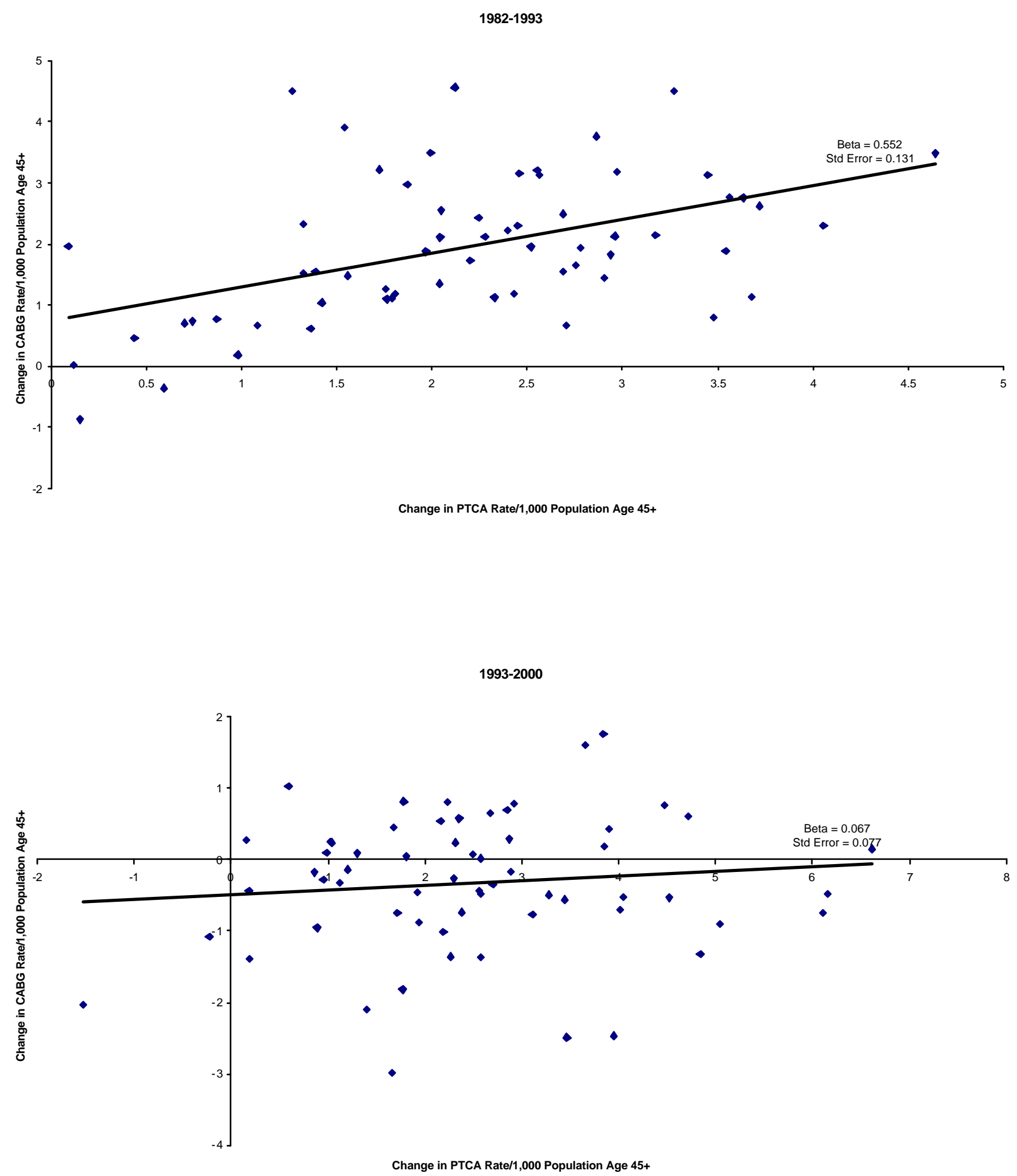

Source: SPARCS Database, 1982-2000. 
Figure 3: Average Cost Per Case for Cardiac Patients in New York State, 1985-1998

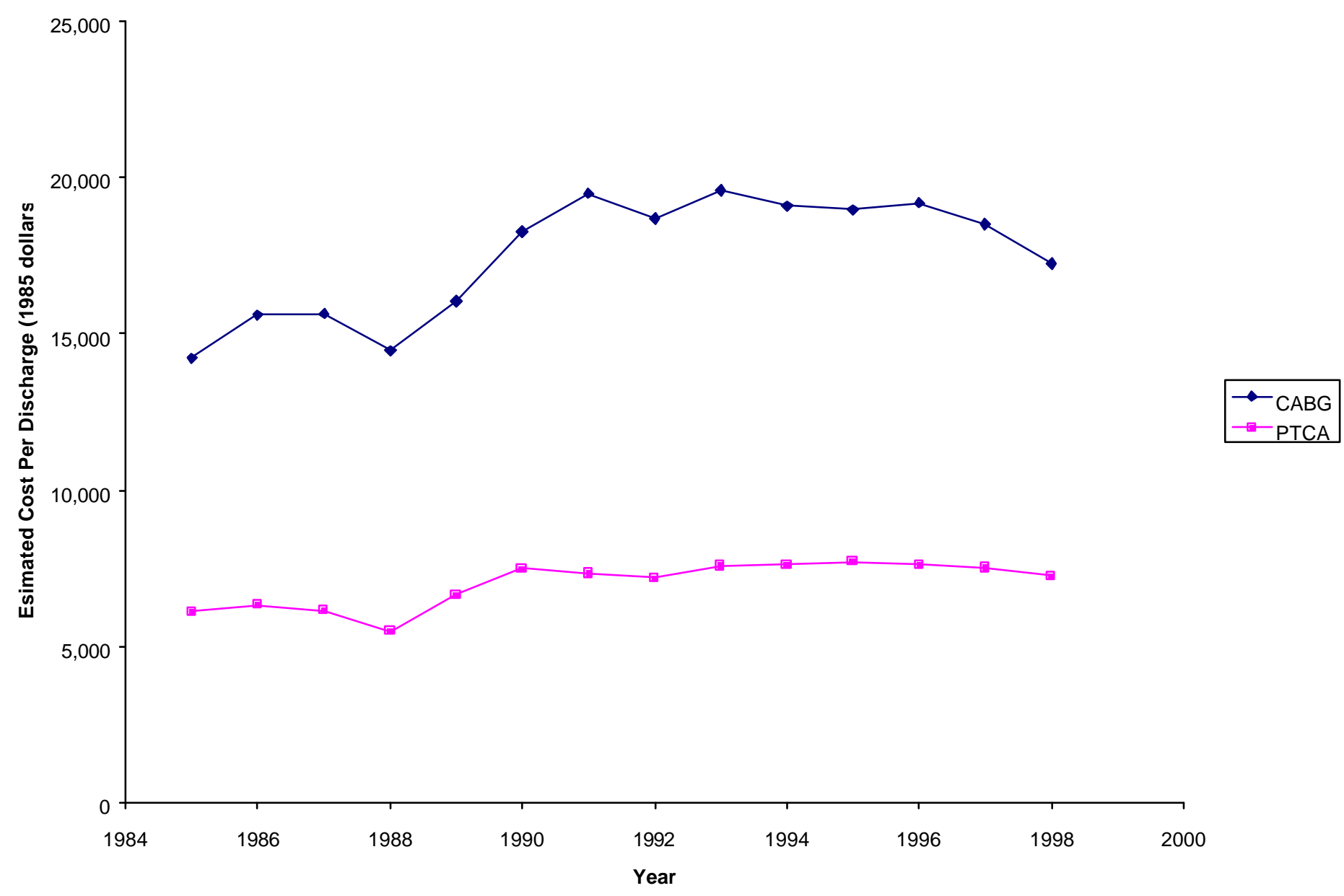

Note: Discharge-level costs are determined by applying the cost-to-charge ratio for a given hospital in a given year to the total gross charges for a given discharge.

Source: SPARCS Database, 1982-2000 and Medicare Hospital Cost Report Database, 1985-1998. 
Figure 4: Cumulative Net Benefit/Cumulative PTCA, 1982-2000

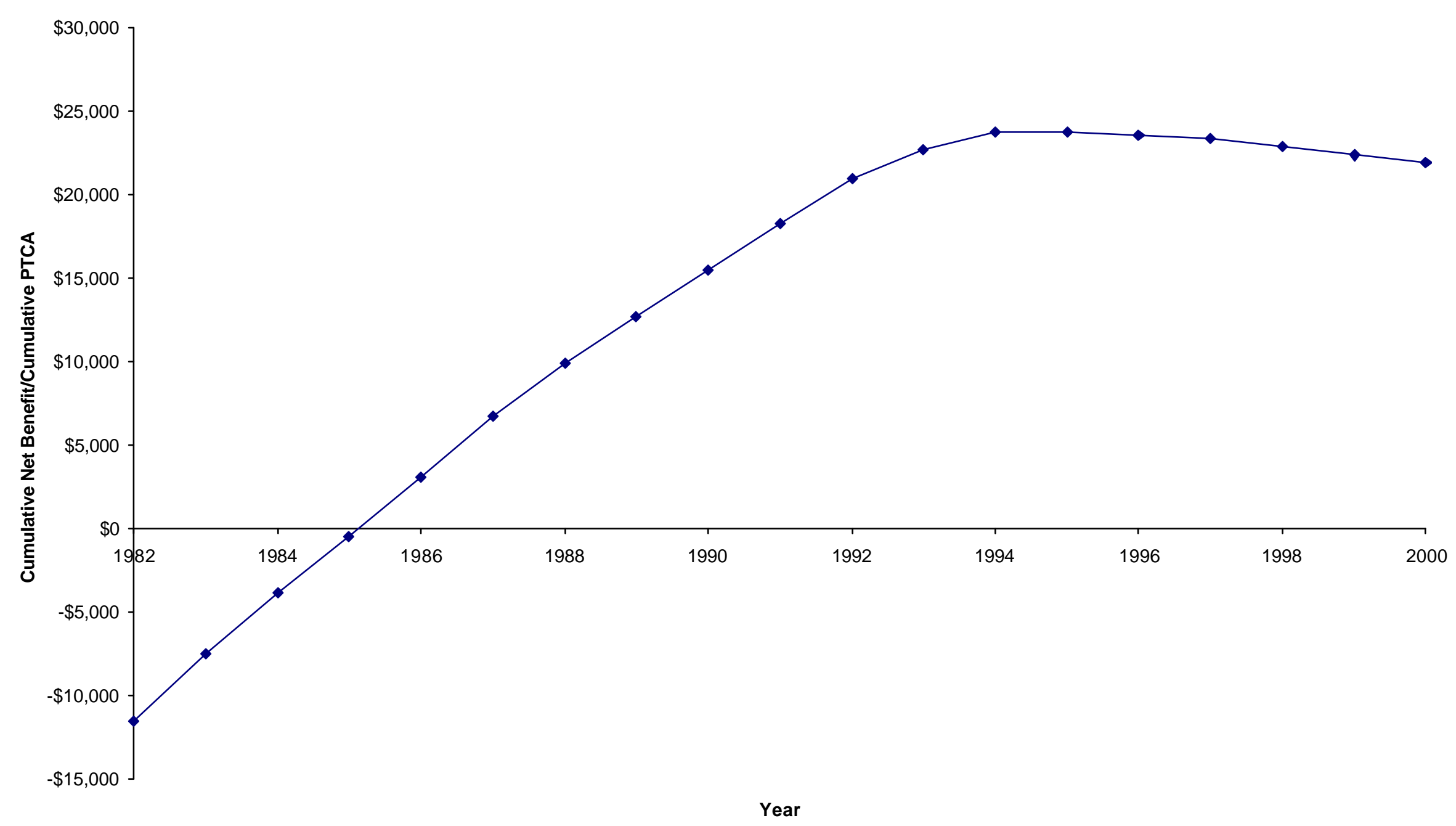

Note: Figures plotted above are the "Cumulative Net Benefit/PTCA" numbers from Table B1. 
Table 1: Number of CABG and PTCA Procedures by Severity Level, 1993-95

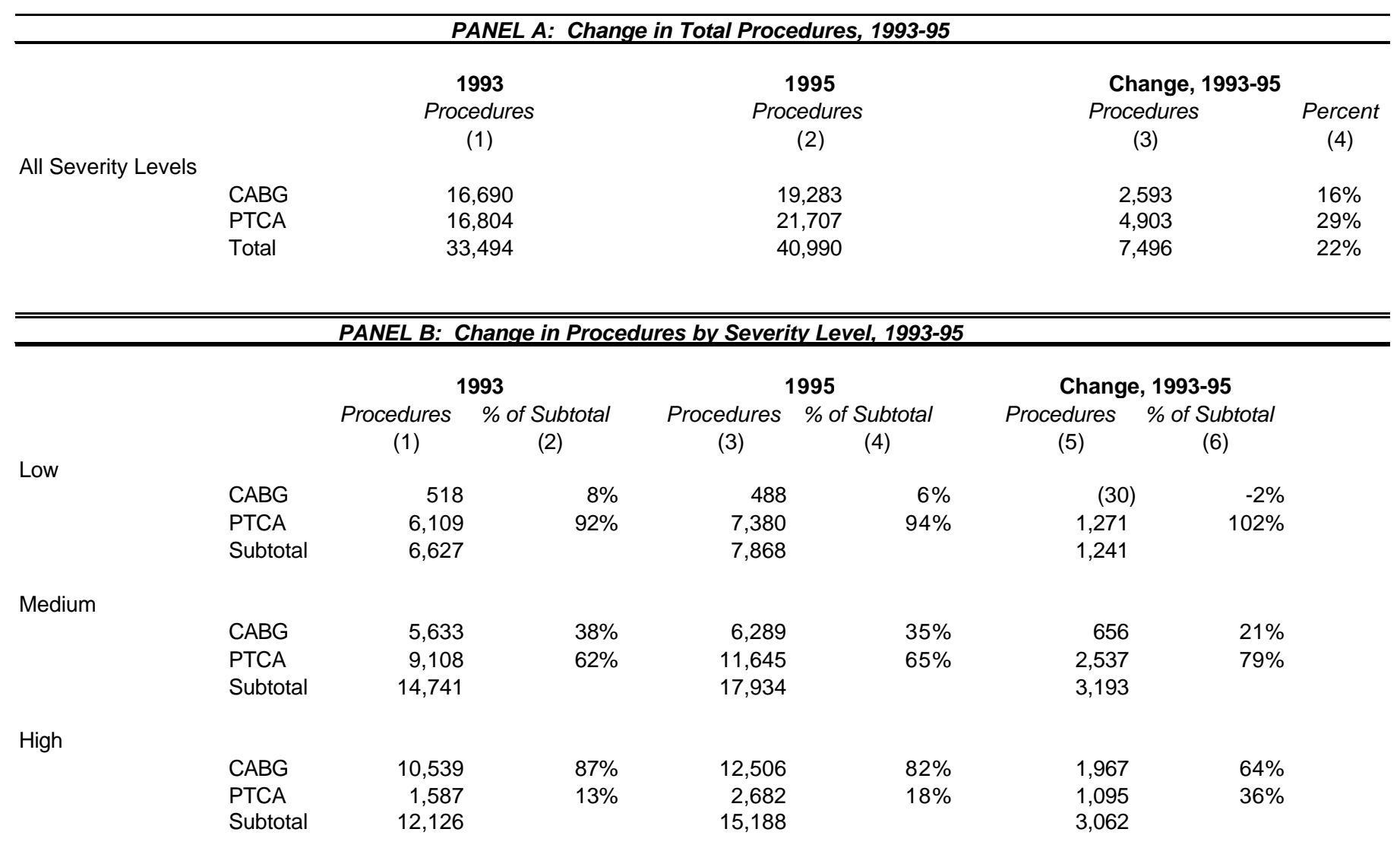

Source: CARS, 1993-1995 and CSRS, 1993-1995. 


\section{Table 2: Levels Regressions}

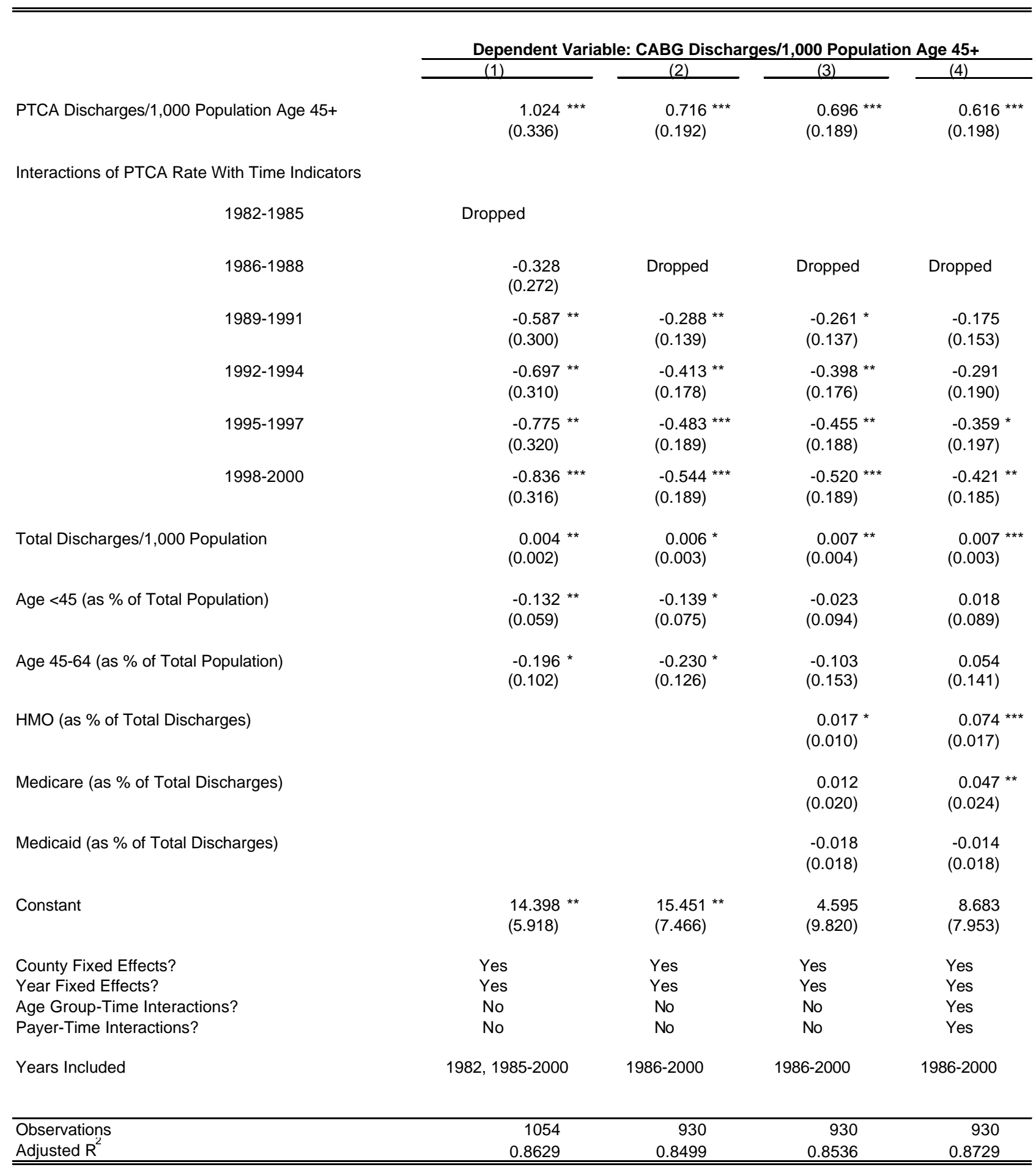

Note: ${ }^{* * *},{ }^{* * *}$ denote statistical significance at the $10 \%, 5 \%$, and $1 \%$ levels, respectively. Observations are weighted by the total number of discharges with a principal diagnosis of either acute myocardial infarction (AMI) or ischemic heart disease (IHD). Standard errors are heteroskedasticity robust and clustered by county of patient residence. 


\section{Table 3: Changes Regressions}

\begin{tabular}{|c|c|c|c|}
\hline & \multicolumn{3}{|c|}{$\begin{array}{c}\text { Dependent Variable: One-Year Change in CABG } \\
\text { Discharges/1,000 Population Age 45+ }\end{array}$} \\
\hline & $(1)$ & (2) & $(3)$ \\
\hline One-Year Change in PTCA Discharges/1,000 Population Age 45+ & $\begin{array}{l}0.393^{* * *} \\
(0.148)\end{array}$ & $\begin{array}{l}0.388^{* * *} \\
(0.152)\end{array}$ & $\begin{array}{l}0.365^{* * *} \\
(0.147)\end{array}$ \\
\hline \multicolumn{4}{|l|}{ Interactions of Change in PTCA Rate With Time Indicators } \\
\hline $1986-1988$ & $\begin{array}{l}-0.304 * \\
(0.185)\end{array}$ & $\begin{array}{r}-0.286 \\
(0.185)\end{array}$ & $\begin{array}{r}-0.241 \\
(0.179)\end{array}$ \\
\hline $1989-1991$ & Dropped & Dropped & Dropped \\
\hline $1992-1994$ & $\begin{array}{r}-0.228 \\
(0.181)\end{array}$ & $\begin{array}{r}-0.233 \\
(0.184)\end{array}$ & $\begin{array}{r}-0.223 \\
(0.177)\end{array}$ \\
\hline $1995-1997$ & $\begin{array}{l}-0.405^{* *} \\
(0.170)\end{array}$ & $\begin{array}{l}-0.397^{* *} \\
(0.173)\end{array}$ & $\begin{array}{l}-0.387^{* *} \\
(0.171)\end{array}$ \\
\hline $1998-2000$ & $\begin{array}{l}-0.366 \text { ** } \\
(0.156)\end{array}$ & $\begin{array}{l}-0.367^{* *} \\
(0.159)\end{array}$ & $\begin{array}{l}-0.3222^{* *} \\
(0.158)\end{array}$ \\
\hline One-Year Change in Total Discharges/1,000 Population & $\begin{array}{c}0.005 * \\
(0.003)\end{array}$ & $\begin{array}{c}0.005 * \\
(0.003)\end{array}$ & $\begin{array}{l}0.005^{* *} \\
(0.003)\end{array}$ \\
\hline Age $<45$ (as $\%$ of Total Population) & $\begin{array}{l}0.068^{* \star *} \\
(0.021)\end{array}$ & $\begin{array}{l}0.090^{* * *} \\
(0.031)\end{array}$ & $\begin{array}{l}0.105^{* * *} \\
(0.041)\end{array}$ \\
\hline Age $45-64$ (as \% of Total Population) & $\begin{array}{r}0.021 \\
(0.023)\end{array}$ & $\begin{array}{r}0.038 \\
(0.034)\end{array}$ & $\begin{array}{r}0.027 \\
(0.070)\end{array}$ \\
\hline HMO (as \% of Total Discharges) & & $\begin{array}{r}-0.002 \\
(0.004)\end{array}$ & $\begin{array}{r}0.006 \\
(0.006)\end{array}$ \\
\hline Medicare (as \% of Total Discharges) & & $\begin{array}{r}0.001 \\
(0.008)\end{array}$ & $\begin{array}{l}0.029 \\
(0.015)\end{array}$ \\
\hline Medicaid (as \% of Total Discharges) & & $\begin{array}{r}-0.012 \\
(0.008)\end{array}$ & $\begin{array}{l}-0.024^{* * *} \\
(0.010)\end{array}$ \\
\hline Constant & $\begin{array}{l}-5.060^{* * *} \\
(1.687)\end{array}$ & $\begin{array}{l}-6.659 * * \\
(2.767)\end{array}$ & $\begin{array}{l}-6.496 * \\
(3.665)\end{array}$ \\
\hline $\begin{array}{l}\text { County Fixed Effects? } \\
\text { Year Fixed Effects? }\end{array}$ & $\begin{array}{l}\text { Yes } \\
\text { Yes }\end{array}$ & $\begin{array}{l}\text { Yes } \\
\text { Yes }\end{array}$ & $\begin{array}{l}\text { Yes } \\
\text { Yes }\end{array}$ \\
\hline Age Group-Time Interactions? & No & No & Yes \\
\hline Payer-Time Interactions? & No & No & Yes \\
\hline Period-Ending Years Included & $1986-2000$ & $1986-2000$ & $1986-2000$ \\
\hline $\begin{array}{l}\text { Observations } \\
\text { Adjusted } \mathrm{R}^{2} \\
\end{array}$ & $\begin{array}{r}930 \\
0.2111 \\
\end{array}$ & $\begin{array}{r}930 \\
0.2116 \\
\end{array}$ & $\begin{array}{r}930 \\
0.2256 \\
\end{array}$ \\
\hline
\end{tabular}

Note: ${ }^{*}{ }^{* *},{ }^{* * *}$ denote statistical significance at the $10 \%, 5 \%$, and $1 \%$ levels, respectively. Observations are weighted by the total number of discharges with a principal diagnosis of either acute myocardial infarction (AMI) or ischemic heart disease (IHD). Standard errors are heteroskedasticity robust and clustered by county of patient residence. 
Table 4: Impact of Substitution on the Net Cost of 100 Incremental PTCA Procedures

\begin{tabular}{|c|c|c|c|c|}
\hline \multirow{2}{*}{ Number of Additional PTCAs } & \multicolumn{2}{|c|}{$\begin{array}{c}\text { Levels } \\
(1)\end{array}$} & \multicolumn{2}{|c|}{$\begin{array}{c}\text { Changes } \\
(2)\end{array}$} \\
\hline & & 100 & & 100 \\
\hline \multicolumn{5}{|l|}{ Treatment Expansion } \\
\hline Number of PTCA Procedures* & & 75 & & 68 \\
\hline 5-Year Net Cost/PTCA--Expansion & $\$$ & 7,872 & $\$$ & 7,872 \\
\hline Subtotal Cost for Treatment Expansion & $\$$ & 593,511 & $\$$ & 535,262 \\
\hline \multicolumn{5}{|l|}{ Treatment Substitution } \\
\hline Number of PTCA Procedures* & & 25 & & 32 \\
\hline 5-Year Net Cost/PTCA--Substitution & $\$$ & $(2,664)$ & $\$$ & $(2,664)$ \\
\hline Subtotal Cost for Treatment Substitution & $\$$ & $(65,534)$ & $\$$ & $(85,248)$ \\
\hline Total Additional Cost & $\$$ & 527,977 & $\$$ & 450,014 \\
\hline Savings from Substitution as $\%$ of Expansion Costs & & $11 \%$ & & $16 \%$ \\
\hline
\end{tabular}

*Based on the change in substitution coefficient from Table 2 between 1989-91 and 1998-2000 periods.

Note: The "5-Year Net Cost/PTCA--Expansion" figure is an estimate of the average additional cost incurred by a patient receiving PTCA relative to one who receives only diagnostic catheterization. It is calculated by adjusting the five-year average cost (inpatient and outpatient) for a PTCA patient with multivessel CAD (\$56,225 in \$1995) from Hlatky et al. (1997). The five-year net cost, PTCA_NETC ${ }_{5 y}$, is calculated as follows:

$$
P T C A_{-} N E T C_{5 y}=P T C A_{-} C O S T_{H, 5 y} *\left(1-\frac{C A T H_{M C R, 5 y}}{P T C A_{M C R, 5 y}}\right)
$$

Where PTCA_COST ${ }_{H, 5 y}$ is the PTCA cost from Hlatky et al. (1997) and the "MCR,5y"subscripts denote five-year, inpatient claims for a $5 \%$ sample of AMI patients (initially admitted in 1994) covered by Medicare. Specifically, $\mathrm{CATH}_{M C R, 5 y}$ represents the average claim for patients receiving only catheterization (without revasculariza tion) within 90 days of their initial AMI admission; PTCA ${ }_{M C R, 5 y}$. is the average claim for patients receiving either PTCA only or PTCA and CABG within 90 days of their initial admission. The "5-Year Net Cost/PTCA-Substitution" is simply the five-year average cost for a CABG patient with multivessel CAD $(\$ 58,889)$ from Hlatky et al. (1997) less the five-year average cost for a multi-vessel PTCA patient. 
Table 5: Implications of PTCA for Medical Productivity (2000 Relative to 1989-91 in \$1995)

\begin{tabular}{|c|c|c|c|c|}
\hline \multirow[b]{2}{*}{ Number of Additional PTCAs } & \multicolumn{2}{|r|}{$\begin{array}{c}\text { Levels } \\
(1)\end{array}$} & \multicolumn{2}{|c|}{$\begin{array}{c}\text { Changes } \\
(2)\end{array}$} \\
\hline & & 100 & & 100 \\
\hline Treatment Expansion & & 75 & & 68 \\
\hline Treatment Substitution & & 25 & & 32 \\
\hline \multicolumn{5}{|l|}{ Benefit of Treatment Expansion } \\
\hline Number of Patients Relieved of Angina* & & 13.6 & & 12.2 \\
\hline Benefit Per Patient-Year of Angina Relief** & $\$$ & 20,000 & $\$$ & 20,000 \\
\hline Estimated Survival for PTCA Patient (in years) & & 10 & & 10 \\
\hline Total Benefit of Angina Relief & $\$$ & $2,714,400$ & & ,448,000 \\
\hline Benefit of Treatment Substitution & & - & & - \\
\hline Total Benefit of 100 PTCAs & $\$$ & $2,714,400$ & & 448,000 \\
\hline Total Additional Cost of 100 PTCAs (From Table 4) & $\$$ & 527,977 & $\$$ & 450,014 \\
\hline Net Benefit of 100 PTCAs & $\$$ & $2,186,423$ & & ,997,986 \\
\hline Net Benefit Per PTCA & $\$$ & 21,864 & $\$$ & 19,980 \\
\hline
\end{tabular}

${ }^{*}$ Assumes that $18 \%$ of treatment expansion patients will be relieved of angina as a result of PTCA (Parisi, Folland, and Hartigan, 1992).

${ }^{* \star B}$ Based on improvement of 0.2 QALY per patient-year of angina relief and value of $\$ 100,000$ per QALY. 